Article

\title{
The Potential of X-ray Photoelectron Spectroscopy for Determining Interface Dipoles of Self-Assembled Monolayers
}

\author{
Thomas C. Taucher(1) and Egbert Zojer *(1) \\ Institute of Solid State Physics, Graz University of Technology, NAWI Graz, Petersgasse 16, 8010 Graz, Austria; \\ thomas.taucher@tugraz.at \\ * Correspondence: egbert.zojer@tugraz.at; Tel.: +43-316-873-8475
}

Received: 16 July 2020; Accepted: 13 August 2020; Published: 19 August 2020

check for updates

\begin{abstract}
In the current manuscript we assess to what extent X-ray photoelectron spectroscopy (XPS) is a suitable tool for probing the dipoles formed at interfaces between self-assembled monolayers and metal substrates. To that aim, we perform dispersion-corrected, slab-type band-structure calculations on a number of biphenyl-based systems bonded to an $\mathrm{Au}(111)$ surface via different docking groups. In addition to changing the docking chemistry (and the associated interface dipoles), the impacts of polar tail group substituents and varying dipole densities are also investigated. We find that for densely packed monolayers the shifts of the peak positions of the simulated XP spectra are a direct measure for the interface dipoles. In the absence of polar tail group substituents they also directly correlate with adsorption-induced work function changes. At reduced dipole densities this correlation deteriorates, as work function measurements probe the difference between the Fermi level of the substrate and the electrostatic energy far above the interface, while core level shifts are determined by the local electrostatic energy in the region of the atom from which the photoelectron is excited.
\end{abstract}

Keywords: X-ray photoelectron spectroscopy; XPS; self-assembled monolayer; SAM; collective electrostatics; band-structure calculation; density-functional theory; DFT

\section{Introduction}

In the field of organic electronics, chemically bonded self-assembled monolayers (SAMs) have been used to change the electronic properties of a huge variety of interfaces [1-18]. They have allowed the realization of n-type organic transistors by screening interface traps [3], they have been used to shift turn-on voltages of devices by several dozens of volts via the introduction of polar and reactive groups into transistor channels [4-7], and they have been employed for tuning injection barriers by adsorption on electrode surfaces, changing contact resistances by orders of magnitude [8-18]. Especially for the latter applications, the shift in the (electrostatic) energy landscape generated by the SAM is of crucial importance. On the one hand, this shift is a consequence of the intrinsic dipoles of the adsorbed molecules due to polar groups (like carboranes, pyrimidines, aromatic sulfones and sulfides, or esters) embedded into the molecular backbones $[15,17,19-23]$ or due to polar tail group substituents (like halogens, amines, nitriles, nitro groups, pyrimidines, alcohols, ethers, or carboxylic acids) [9,24-38]. On the other hand, there is always an interface dipole localized in the immediate contact region between the substrate and the adsorbed molecule, as discussed in a variety of experimental and theoretical studies $[11,25,27,28,31,32,39-44]$. This interface dipole consists of the surface dipole of the (metal) substrate, the dipole associated with the (typically polar) docking group, and the bond dipole due to interfacial charge rearrangements following bond formation. The superposition of the 
electric fields due to the interface dipoles of all adsorbed molecules causes a step in the electrostatic energy, as explained in detail in several review papers [31,40,42,45,46]. This step in electrostatic energy triggers a shift in the position of the vacuum level above the surface and, consequently, as the most common observation, changes the sample work function $[8,11,14-17,19,21,22,25,27,28,31,32,35,39,41,43,44$, 47-52]. Additionally, theoretical as well as experimental studies reveal that it modifies the interfacial energy-level alignment, i.e., the positions of the electronic states of the adsorbed monolayer relative to those of the substrate $[27,28,31,39,40,42,45-47,53-62]$. A change in the interfacial level alignment has an immediate impact on charge-transport through the adsorbed layer [53-62] and also on the positions of the core levels of the adsorbate [42]. The latter has been primarily discussed for embedded dipole SAMs, with a focus on shifts caused by esters $[20,63,64]$ or pyrimidines $[21,22,48,49]$. Notably, El-Sayed et al. also used it to assess the level alignment in mixed monolayers consisting of flat-lying donor and acceptor molecules [65].

Changes in core level binding energies can be probed by X-ray photoelectron spectroscopy (XPS) [66-70], which is one of the default techniques for characterizing SAMs, used, for example, for analyzing the quality of self-assembled monolayers and to verify bonding [67,71-82]. In this paper we will argue that the electrostatic core level shifts make XPS an ideally suited tool for probing interface dipoles. For supporting that claim, we will use state of the art quantum-mechanical simulations to determine core level shifts encountered in biphenyl-based SAMs attached to an $\mathrm{Au}(111)$ substrate by a variety of chemically different docking groups. To the best of our knowledge, a corresponding set of experimental XPS data with systematically varied docking groups and consistent film structures and morphologies does not exist yet. Nevertheless, first steps in that direction have been undertaken and biphenyl-based SAMs on various metallic substrates have been studied, albeit with a clear focus on thiol docking groups $[60,73,81-89]$. We, however, do not consider this to be an all too serious problem for a study focusing on the conceptual physical aspects that allow a determination of interface dipoles by XPS. Moreover, we have high confidence in the employed computational approach, which is described in the following section. This confidence is based on the fact that in the past we have performed several joint theoretical and experimental studies on aliphatic $[63,64]$ and aromatic $[22,48,49]$ SAMs bonded to the substrate by thiol and dithiocarbamate [90] groups, for which we observed an excellent agreement between measured and simulated core level shifts.

In the present study we will show that core level spectroscopy is not only useful for measuring chemical shifts or to explore the role of dipoles contained in the adsorbates. Rather, it can also be used as a tool for systematically determining the "interface dipole" at the interface between a substrate and an adsorbate.

\section{Computational Methodology}

The structural and electronic properties of the metal-SAM interfaces were simulated by density functional theory (DFT) employing the all-electron, full potential FHI-aims code (version 190715 [91-95] (see also aimsclub.fhi-berlin.mpg.de) and periodic boundary conditions. The Perdew-Burke-Ernzerhof (PBE) $[96,97]$ functional was used for describing exchange and correlation. Furthermore, long-range van der Waals interactions were accounted for by employing the surface version [98] of the Tkatchenko-Scheffler dispersion correction [99], which was specifically parameterized for treating adsorbing molecules on metal substrates. The dispersion correction between the Au atoms of the metal slab was turned off. All calculations were done with the so-called tight basis set for all atomic species (as supplied by FHI-aims). A thorough description of the corresponding basis functions is included in the Supplementary Materials. Reciprocal space was sampled by a converged $\Gamma$-centered $15 \times 10 \times 1$ grid for the full coverage systems and by accordingly smaller sized grids for larger super cells. The change of the volume-integrated electron density was converged to $10^{-5} \mathrm{e}^{-}$and the total energy to $10^{-6} \mathrm{eV}$.

Interfaces were modeled employing the repeated-slab approach with the $\mathrm{Au}(111)$ substrate represented by five metal layers. The bottom three Au layers were kept fixed in all calculations to avoid 
spurious relaxations at the bottom surface. The periodic replicas of the slabs were quantum-mechanically and electrostatically decoupled by a vacuum gap of more than $20 \AA$ and a self-consistent dipole correction $[100,101]$. The geometries of the adsorbate molecules and the top two Au-layers in the full coverage unit cells were fully relaxed until the remaining forces on each atom were below $10^{-3} \mathrm{eV} / \AA$. The geometries of the other supercells considered here were directly derived from the full coverage unit cell by replicating it in $x$ - and $y$-directions and removing all but one molecule from the resulting cell (see Supplementary Materials). These supercells were considered as model systems to study the impact of diluting the interfacial dipoles. Thus, we fixed the remaining molecule in the geometry it adopts in the densely packed layer to prevent it from falling over [102].

The change of the work function was obtained from the difference of the calculated work functions at the bottom side of the $\mathrm{Au}(111)$-slab $\left(\Phi_{\mathrm{Au}}=5.10 \mathrm{eV}\right.$ for all systems) and above the self-assembled monolayer. Furthermore, the work function change of the nominally non-interacting system, i.e., the SAM without a docking group moved $1 \AA$ away from the substrate compared to its equilibrium adsorption distance (see Section 3.2), was defined as a reference point relative to which the work function changes $(\Delta \Phi)$ for all other systems are reported. The difference between lower and upper slab work function for the reference system amounts to $\delta \Phi_{\text {ref }}=-0.11 \mathrm{eV}$.

The core level binding energies were calculated using the initial state approach, relying on the Kohn-Sham eigenvalues of the respective orbitals. This approach does not provide absolute values of the core level binding energies, but yields relative shifts between different systems $[65,68,103-108]$. We have also found it to provide a very good description of core level shifts in SAMs $[21,22,48,49,63,64]$. In fact, when modeling the X-ray photoelectron (XP) spectra of (partially) aromatic hydrocarbon SAMs bonded to Au substrates, we typically find that shifting the calculated spectra to higher binding energies by between 18.9 to $19.0 \mathrm{eV}[22,49,90,109]$ yields an excellent correlation with experimental data. Therefore, throughout the manuscript (like for the work functions) core level shifts are reported relative to the nominally non-interacting reference system consisting of a SAM without the docking group moved $1 \AA$ away from the substrate compared to its equilibrium adsorption distance (see Section 3.2). The calculated value of that reference energy was $-263.95 \mathrm{eV}$.

Another complication when employing the initial-state approach is that (in contrast to final-state approaches) $[68,70,110,111]$ it does not account for core hole screening effects. Unfortunately, final-state approaches are not applicable to systems like the ones considered here, as in conjunction with periodic boundary conditions one would need unit cells comprising of thousands of atoms in order to avoid spurious collective electrostatic effects due to periodic replicas of the core holes (and the compensation charges) $[63,112]$. Therefore, we resorted to an a posteriori correction of screening by the metal substrate relying on an image charge model, which is explained in detail in the Supplementary Materials $[113,114]$. In passing we note that screening by the metal substrate has only a comparably minor impact on the spectra shown below, as we are dealing with rather extended, upright standing molecules, whose spectra are dominated by excitations of atoms, which are rather far away from the substrate. To account for the finite escape depth of the photoelectrons from lower-lying atoms, we scaled their contributions by an exponential attenuation function [115] setting the incident photon energy to $580 \mathrm{eV}$, as described in detail in the Supplementary Materials. To obtain the final spectra, the discrete peaks were convoluted with a Gaussian function with a variance of $0.3 \mathrm{eV}$. A flowchart summarizing the simulation procedure can be found in the Supplementary Materials. Furthermore, for the sake of reproducibility, we also provide all FHI-aims input and output files for all simulations contained in this manuscript. The data set has been uploaded to the NOMAD database and can be accessed and downloaded via the doi: 10.17172/NOMAD/2020.08.13-1.

For the analysis and visual representation of the data, Python was used in combination with NumPy [116] and matplotlib [117]. Ovito [118] was applied for generating the 3D view of the systems and for the 2D potential plot we used VESTA [119]. Finally, the figures were compiled with GIMP [120]. 


\section{Results and Discussion}

\subsection{Energetics of a Metal-SAM Interface}

For understanding the correlation between XP spectra and interface dipoles, it is useful to first consider how interface dipoles impact the electronic properties of a system consisting of an inorganic substrate and a chemically bonded monolayer (formed by upright-standing molecules). For the sake of simplicity, in the following we will focus on metal substrates. In this way, further complications due to band-bending effects $[35,63,121,122]$ in semiconducting substrates (and their modification by the adsorbate layer) can be avoided.

A schematic representation of the electronic structure of the metal-SAM interface is shown in Figure 1 for the case of a SAM in which an interface dipole occurs (virtually all SAMs) and in which also a functional tail group is used bearing a tail group dipole. Due to the superposition of the fields generated by the dipoles in the densely packed monolayer (i.e., due to collective electrostatic effects) $[27,31,40,42,45,46,63,123,124]$, steps in the electrostatic energy occur. The steps due to the interface dipole, ID, and due to the tail group dipole, TD, are indicated by vertical blue arrows. The sum of these two energy shifts causes the change in substrate work function due to monolayer adsorption, $\Delta \Phi$. Conversely, only the interface dipole is responsible for the change in injection barriers, $\Delta \mathrm{IB}$, which determines the final electron- and hole-injection barriers, EIB and HIB, respectively. The core levels are shifted in line with the frontier levels. Consequently, the interface dipole should result in a shift of the positions of the core levels relative to the Fermi level of the substrate, $\Delta \mathrm{E}_{\mathrm{C} 1 \mathrm{~s}}$, that is equivalent to $\triangle \mathrm{IB}$. This shift is directly translated into a modification of the kinetic energies of the electrons, $E_{\text {kin }}$, and, thus, in a shift of the XP spectra.

In this context it is important to stress that the above considerations disregard energetic shifts due to interfacial charge transfer processes, which could significantly modify the energies of strongly localized orbitals (i.e., the core levels). Indeed, for the atoms in a SAM that are in the immediate vicinity of the interface, such a charge transfer typically modifies the core level binding energies $[68,69,125,126]$, which has also been observed for simulations on SAMs [90]. In experiments on extended, upright standing molecules it will, however, be often inconsequential for the measured spectra, as the atoms in the immediate vicinity of the interface mostly affected by these "chemical" shifts hardly contribute to the measured spectra, especially when using primary photon energies of a few hundred $\mathrm{eV}$ in synchrotron measurements. This is a consequence of the finite escape depth of the photoelectrons. The situation changes for experiments with typical lab sources with primary photon energies of, e.g., $1253.6 \mathrm{eV}(\mathrm{Mg}-\mathrm{K} \alpha)$ and $1486.6 \mathrm{eV}(\mathrm{Al}-\mathrm{K} \alpha)$, for which the attenuation length can be larger than the typical thickness of SAMs. Thus, for properly resolving the electrostatic shifts discussed her, the said synchrotron experiments are preferable (also because of the often higher energy resolution).

Finally, it should be mentioned that in the absence of an energetic shift due to a tail group dipole (or when comparing differently docked systems with identical tail group dipoles), the above considerations imply that SAM-induced changes of the substrate work function should directly correlate with shifts in core level binding energies. Below, we will test under which circumstances such a situation is encountered at a metal-SAM interface. 

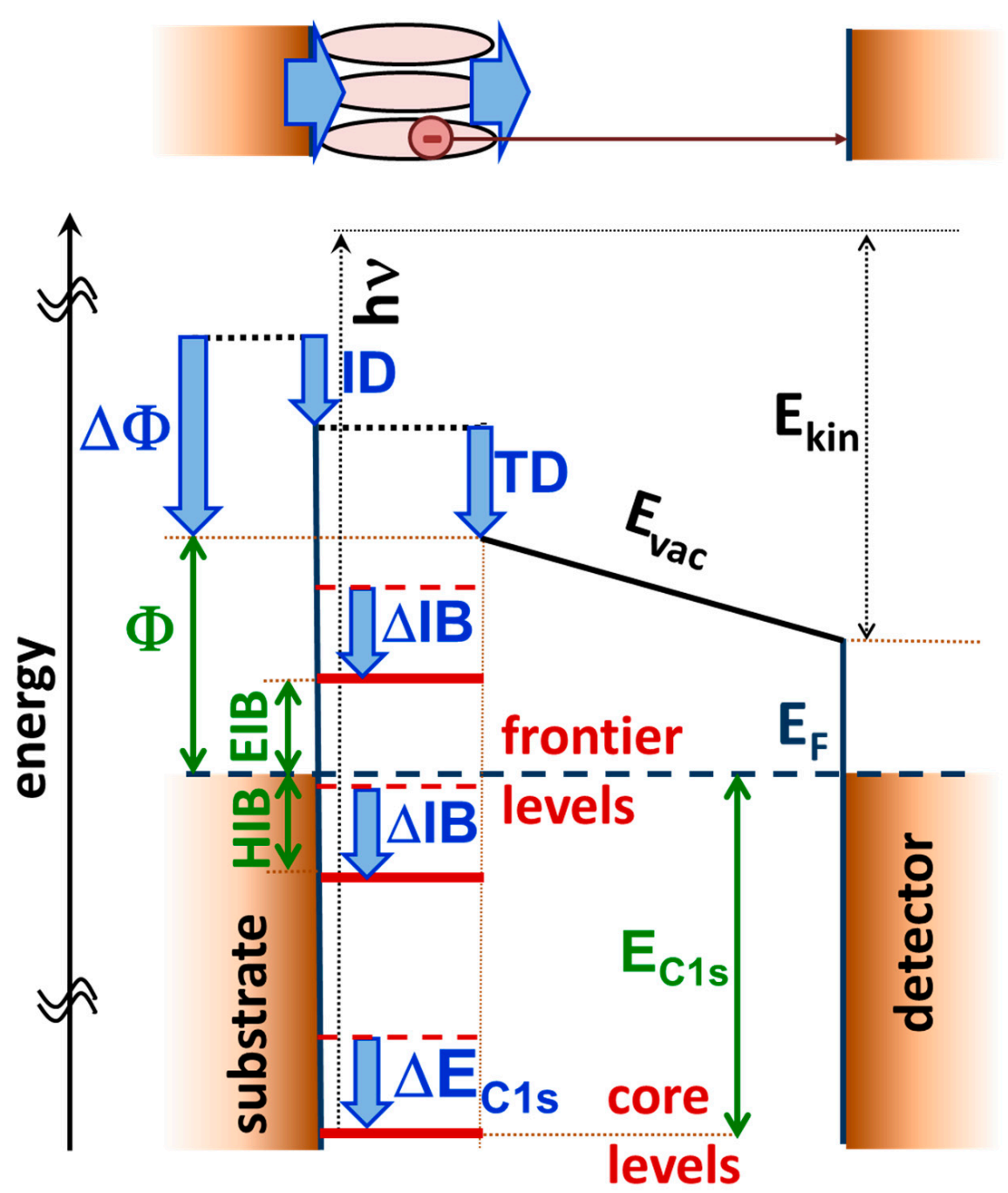

Figure 1. Schematics of the energy landscape of a metal-self-assembled monolayer (SAM) interface and an XPS experiment (disregarding the bias voltage applied between substrate and detector). The interface electronic structure is characterized by the work function, $\Phi$, by the alignment of the frontier levels determining electron- and hole-injection barriers, EIB and HIB, and by the energetic positions of the core levels, here exemplarily denoted as $\mathrm{E}_{\mathrm{C} 1 \mathrm{~s}}$. The shift of the electrostatic energy due to the interface dipole, $\mathrm{ID}$, determines the changes in the injection barriers, $\Delta \mathrm{IB}$, and the core level shifts, $\Delta \mathrm{E}_{\mathrm{C} 1 \mathrm{~s}}$. The work function change, $\Delta \Phi$, is additionally influenced by the energetic shift due to the tail group dipole, TD. Absorption of an X-ray photon with energy hv creates a photoelectron, which at the position of the detector has a kinetic energy of $\mathrm{E}_{\mathrm{kin}}$. Additional positive potentials (not included in the plot) applied to the detector relative to the substrate increase the measured kinetic energy of the photoelectron. The top panel sketches the metal-SAM interface, whose properties are determined by the interface and the tail group dipole. In passing we note that the actual situation can be further complicated, e.g., when additional dipoles are contained along the backbones of the molecules [15,17,19-22].

\subsection{Investigated Systems}

To assess the possibility of probing bond dipoles by X-ray photoelectron spectroscopy, we simulated SAMs on $\mathrm{Au}(111)$ surfaces, as such systems have been studied extensively $[71,72,74,79,127]$, which qualifies them as prototypical model systems. As molecular backbones we chose biphenyls with two molecules per $(3 \times \sqrt{3})$ rect surface unit cell arranged in a herringbone structure [85]. As docking groups we considered thiolates (system I) [71,72,74,79], methyl thiolates (system II) [71,72,74,79], pyridines (system III) [54,128-133], isocyanides (system IV) [39,133-135] and cyanides (system V). The structures 
of all investigated systems can be seen in Figure 2. Furthermore, for the sake of comparison, we also simulated an upright-standing biphenyl layer not bearing a dedicated docking group (system VI), which represents a metastable structure, as the equilibrium configuration for the biphenyl-Au interface would very likely be flat-lying molecules. Due to different interfacial charge rearrangements and intrinsic dipole moments associated with the docking groups in these six systems, we expect distinct variations of the respective interface dipoles. Notably, in system VI, the only reason for an interface dipole would be Pauli-pushback $[47,136,137]$. To eliminate also that effect and to generate an essentially dipole-free interface, we also considered a system with the biphenyl layer shifted by $1 \AA$ further away from the substrate (system VIa). In passing we note that increasing the distance from the substrate by yet another $1 \AA$ does not change the spectrum (see Supplementary Materials). The electronic structure of system VIa is essentially identical to what is obtained when assuming vacuum-level alignment between an $\mathrm{Au}(111)$ surface and a free-standing biphenyl monolayer (the calculated work function reduction is on the order of $0.1 \mathrm{eV}$; for further information see Supplementary Material). Additionally, we considered two systems bearing electron accepting (system VII) and electron donating (system VIII) tail group substituents. These are known to change the work function without affecting the alignment of the frontier levels [27].
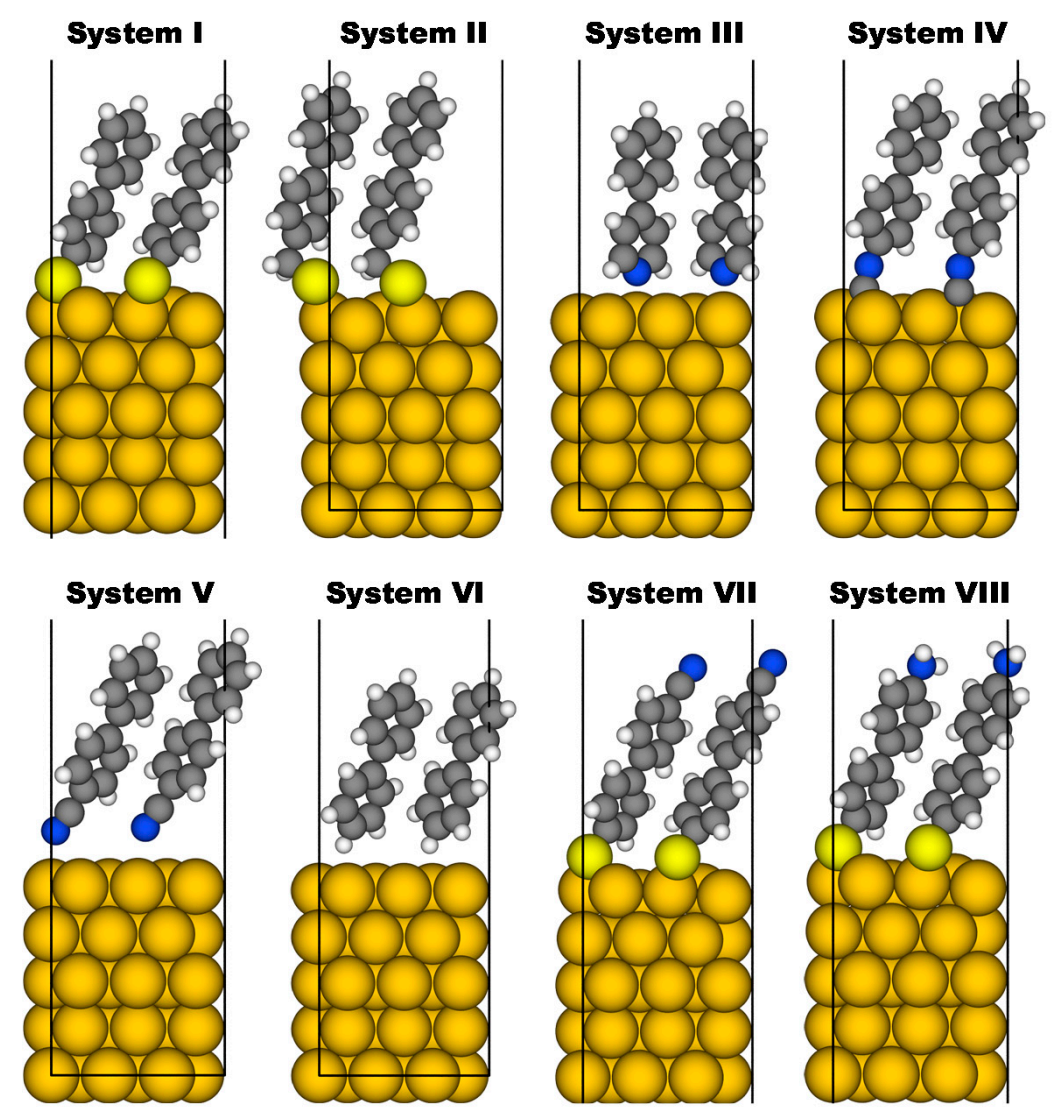

Figure 2. Front view of the unit cells investigated in the present study. The self-assembled monolayers are all derived from a biphenyl backbone and bear different docking groups (Systems I to VI) or different tail groups (System VII and VIII). The SAMs are bonded to an Au(111) metal slab consisting of 5 layers of gold atoms. The docking groups comprise of thiolate (System I), methyl-thiolate (System II), pyridine (System III), isocyanide (System IV) and cyanide (System V). System VI is an upright standing biphenyl layer not bearing any docking group. Systems VII and VIII are both bonded via thiolates, but contain different (polar) tail groups (a nitrile in the case of system VII and an amine in the case of system VIII). The molecules are arranged in a herringbone pattern, as can be seen in the top views of the unit cell shown in the Supplementary Materials. Color code: dark yellow: Au, bright yellow: S, grey: $C$, blue: $N$, and white: $H$. 


\subsection{Calculated Core-Level Binding Energies, XP Spectra, and Work Function Changes}

\subsubsection{Energetic Shifts Due to Variations in the Interface Dipole}

In Figure 3, we show the core level binding energies and XP spectra of systems I, III, V, and VIa as prototypical examples for the impact of the docking groups on the core level binding energies. In the following, the "vacuum level alignment" system VIa was used as an energy reference for the work function as well as for the core level binding energies (for the absolute values of the reference energies see the Methods Section). This directly yields $\Delta \mathrm{E}_{\mathrm{C} 1 \mathrm{~s}}$ and $\Delta \Phi$ (i.e., the quantities shown in Figure 1). As far as the systems not displayed in Figure 3 are concerned, the data points for II essentially coincide with those of I and (apart from chemical shifts for the carbon atoms directly bonded to nitrogen atoms) the binding energies of III and V are also similar. System VI is similar to VIa with binding energies shifted to higher values by $0.34 \mathrm{eV}$. The corresponding data can be seen in the Supplementary Materials, where we show a (somewhat busy) plot analogous to Figure 3 containing values for all investigated systems. Compared to System VIa, the core level binding energies in all chemically bonded SAMs are shifted to higher (more negative) binding energies by several electronvolts. The effect is largest for III, for which the shift amounts to $2.8 \mathrm{eV}$ (see black arrow). Even between docked systems, the peak positions vary by $1.6 \mathrm{eV}$ with the smallest value $(-265.2 \mathrm{eV})$ for the methyl thiolate and the largest $(-266.8 \mathrm{eV})$ for the pyridine. This is exactly the situation one would expect according to Figure 1 for varying interface dipoles as a consequence of collective electrostatic effects $[31,40,45,46,63]$.

In passing we note that, to the best of our knowledge, there is no systematic experimental study of docking group induced shifts in a series of well-ordered monolayers, but there are examples comparing thiols and isocyanides: Zangmeister et al. compared 4,4'-ethynylphenyl-1-benzenethiols on polycrystalline Au bonded either by thiols or by isocyanides and for the isocyanide-docked SAMs they observed a C1s peak at $0.6 \mathrm{eV}$ higher binding energy than for the thiol case [138]. There is also indirect evidence that such shifts occur in other types of SAMs: when comparing thiolate and isocyanide bonded acene SAMs, Kim et al. measured a distinctly larger ionization energy of the isocyanide-bonded system with the shift between the valence orbitals amounting to $0.7 \mathrm{eV}$ [139]. Unfortunately, they did not report corresponding $\mathrm{C} 1 \mathrm{~s}$ core level spectra, but, as discussed above, the shifts of valence and core levels have the same physical origin. Overall, the results in $[138,139]$ are well in line with the data for systems I and IV in Figure 3, where the somewhat larger shift in the simulations is presumably due to assumed perfect ordering of the SAMs.

Superimposed on the electrostatic shifts of the XPS peaks, one can also identify the chemical shifts due to the differently bonded carbon atoms (cf. Figure 3a). For example, the carbon atoms connecting the two benzene rings are shifted by $0.5 \mathrm{eV}$ relative to the other carbon atoms of the rings. Additionally, the carbon atoms attached to the docking groups are chemically shifted, resulting in distinct variations of the binding energies. This is, however, rather inconsequential for the positions and shapes of the XP spectra as a consequence of the finite escape depth of the photoelectrons. This is well visible, for example, for the isocyanide-docked SAM (system IV), where the lowest carbon atoms are shifted by $2 \mathrm{eV}$ relative to the ones in the rings. The latter still rather exclusively determine the position of the peak in the corresponding XP spectrum.

Provided that the primary core level shifts are truly a consequence of collective electrostatic effects caused by interface dipoles they should directly correlate with the SAM-induced changes in the work function for systems I to VIa. To test that, we plotted $\Delta \Phi$ as a function of $\Delta \mathrm{E}_{\mathrm{C} 1 \mathrm{~s}}$ for all investigated SAMs in Figure 4. Indeed, the data for all SAMs without polar tail group substituents align perfectly along a straight line with a slope of 1 passing through the origin. This supports the assessment that in these systems core level shifts and work function changes have the same origin (namely the interface dipole). In passing we note that the dipole due to the terminal C-H bond of the biphenyl cancels out for the evolution of $\Delta \Phi$ vs. $\Delta \mathrm{E}_{\mathrm{C} 1 \mathrm{~s}}$ (at least for similar coverages and tilt angles), as the non-interacting biphenyl monolayer is used as the reference for both quantities. 
(a)

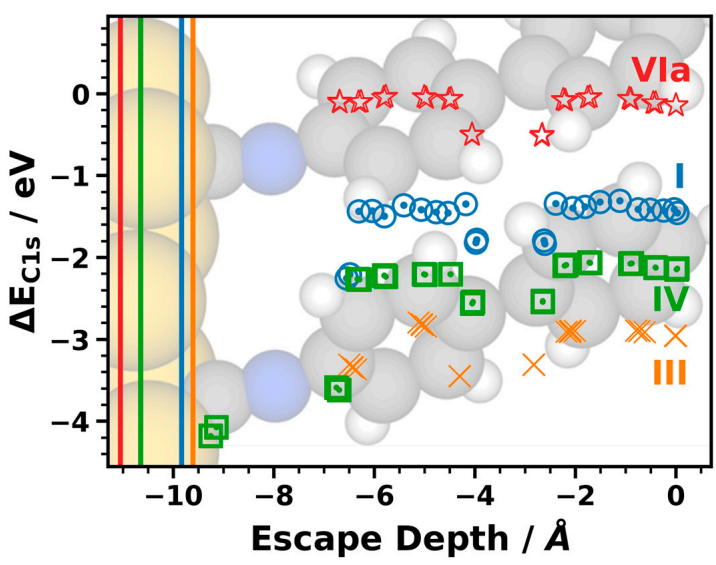

(b)

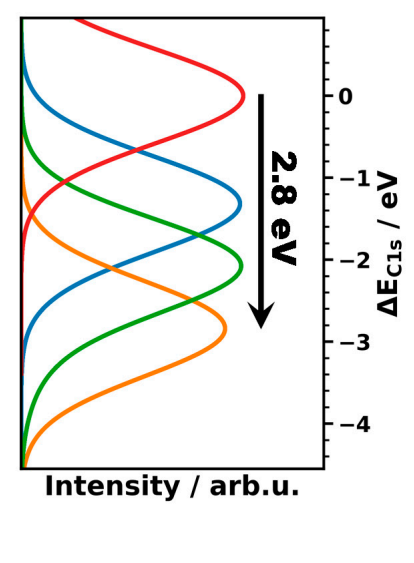

Figure 3. (a) Simulated shifts of carbon 1 s orbital energies, $\Delta \mathrm{E}_{\mathrm{C} 1 \mathrm{~s}}$, as a function of the escape depth of the electrons for the prototypical systems I, III, IV, and VIa and (b) the corresponding XP spectra generated from the calculated energy levels. The energy scale is chosen relative to the position of the peak in the XP spectrum for the vacuum-level aligned system VIa. The escape depth defined as the distance from the topmost carbon atom is chosen as the parameter on the $x$-axis considering that the highest atoms primarily determine the XP spectra. As the extent of the SAMs between the bottom ring and the metal substrate varies due to the different docking groups, this choice of the $x$-axis also largely aligns biphenyls in the different systems. System IV is shown in the background as an example of the structure of one of the SAMs considered in the plot. Due to the different SAM thicknesses, we included vertical lines in panel (a), which designate the positions of the centers of the atoms of the topmost Au layer. The large number of data points for each system is a consequence of the two inequivalent molecules per unit cell.

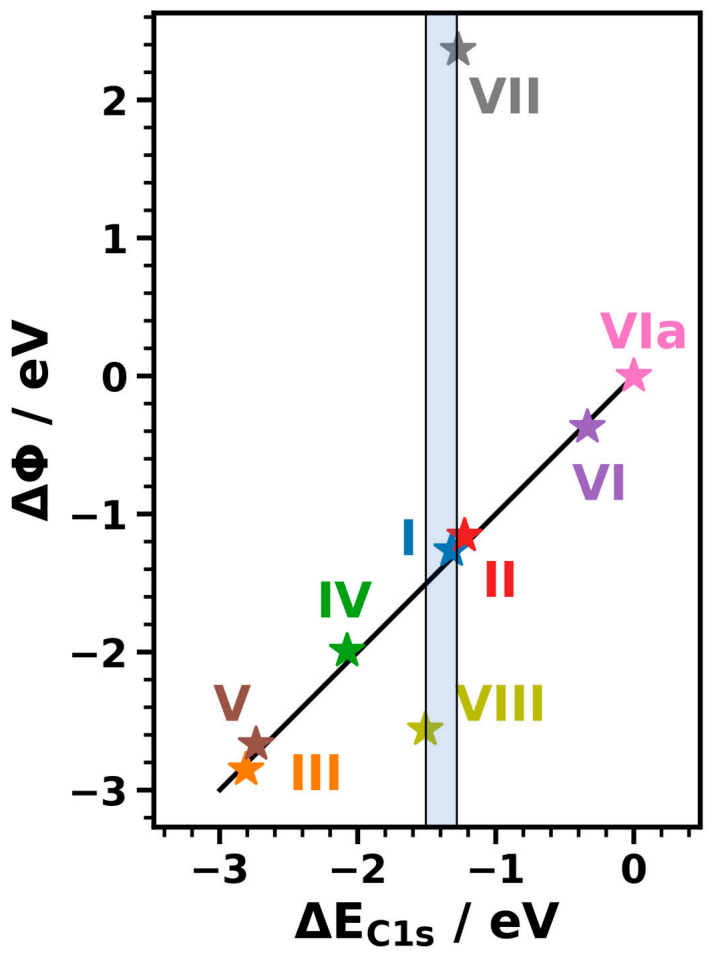

Figure 4. Correlation between the change in work function, $\Delta \Phi$, and the shift in binding energy, $\Delta \mathrm{E}_{\mathrm{C} 1 \mathrm{~s}}$, for all systems relative to system VIa (as non-interacting reference system in which no interface dipole occurs). The black line indicates a linear curve with a slope of 1 through the origin. The shaded area represents the range over which the values for $\Delta \mathrm{E}_{\mathrm{C} 1 \mathrm{~s}}$ vary between systems I, VII, and VIII. 


\subsubsection{Influence of Different Tail Groups on the XP Spectra}

This raises the question, what would happen if the SAM-forming molecules were substituted with tail groups bearing dipoles significantly different from the terminal C-H bond of a phenyl ring. According to Figure 1, this should (significantly) modify the work function shift, while leaving the core level binding energies essentially unchanged, with the exception of chemical shifts experienced by carbon atoms in or directly bonded to the substituents. To test that hypothesis, we simulated systems VII and VIII containing - $\mathrm{CN}$ and $-\mathrm{NH}_{2}$ tail groups. As far as the simulated core level binding energies are concerned, we find them to be very similar for all three systems (I, VII, and VIII), as shown in Figure 5. Concerning the chemically shifted C1s binding energies of the uppermost carbon atoms, for system VII the shift of the top carbon atoms in the phenylene and the carbons in the -CN groups go in opposite directions. Thus, their impacts on the XP spectrum essentially cancel. As a consequence, the peak position of the C1s XP spectra of I and VII are virtually the same. Additionally, in VIII the shift of the peak remains comparably small (amounting to only $0.19 \mathrm{eV}$ ), as there are only the topmost carbon atoms in the two molecules per unit cell that are affected by the presence of the amine. This means that for all systems considered in the present study, the position of the peak in the C1s spectrum is a valid measure for the interface dipole.

(a)

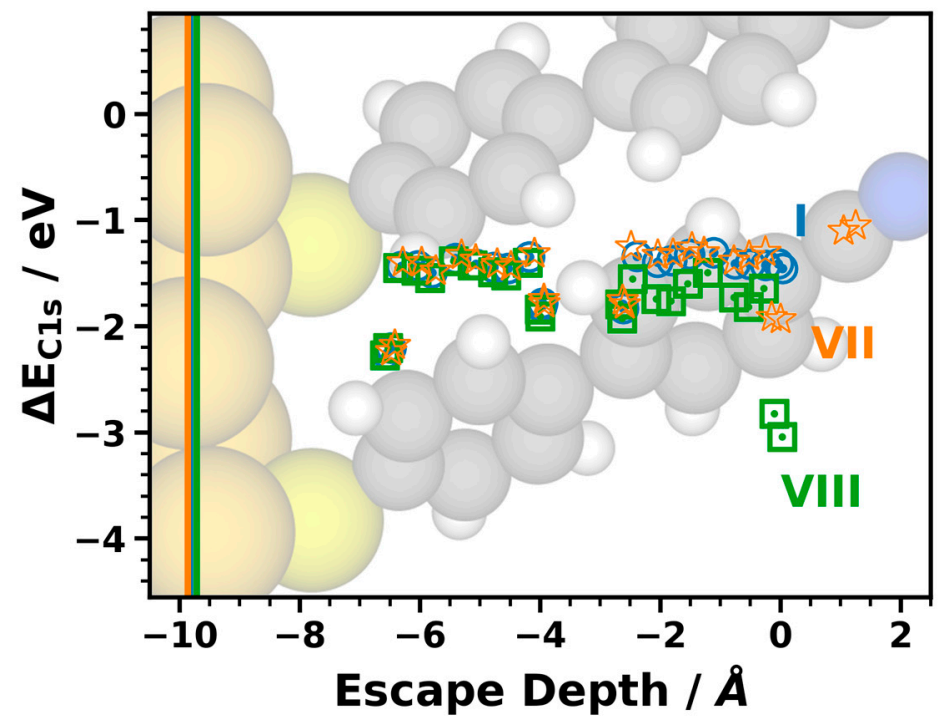

(b)

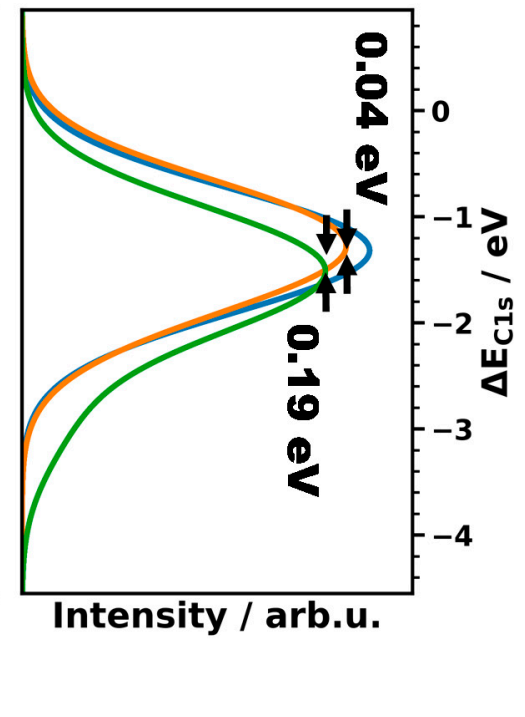

Figure 5. (a) Simulated shifts of carbon 1 s orbital energies, $\Delta \mathrm{E}_{\mathrm{C} 1 \mathrm{~s}}$, as a function of the escape depth of the electrons for the equally docked systems I, VII, and VIII and (b) corresponding XP spectra generated from the calculated energy levels. As the substituents significantly impact the extent of the SAMs above the top ring, but its volume density is rather low, the topmost carbon atom of the benzene ring was chosen as the origin of the $x$-axis. In this way, the axis is consistent with the $x$-axis of Figure 4 and the carbon rings are aligned at essentially the same positions. The large number of data points for each system is a consequence of the two inequivalent molecules per unit cell.

As shown in Figure 4, in sharp contrast to the core level spectra, the work function changes for VII and VIII differ significantly from that of I (by $3.63 \mathrm{eV}$ for VII and by $-1.30 \mathrm{eV}$ for VIII). This is again fully consistent with the model described in Section 3.1.

\subsubsection{Coverage Dependence}

As a last aspect it should be addressed to what extent the above conclusions hold for less densely packed polar layers at the interface $[42,113]$. To assess that, in a gedankenexperiment we constructed hypothetical low-coverage systems with upright-standing molecules (for details see the Methods 
Section and the Supplementary Materials). Based on the Helmholtz solution to the Poisson equation, one would expect a linear dependence of the dipole density and, thus, of $\Delta \Phi$ and $\Delta \mathrm{E}_{\mathrm{C} 1 \mathrm{~s}}$ on coverage. The actual coverage-dependence of $\Delta \Phi$ and $\Delta \mathrm{E}_{\mathrm{C} 1 \mathrm{~s}}$ is shown in Figure 6 for the same systems that had already been considered in Figure 3. Interestingly, one observes that $\Delta \Phi$ changes much more strongly at low than at high coverages. This is a consequence of depolarization effects. These strongly reduce the interface dipoles at high coverages [140-148]. Therefore, work function changes at full coverages are strongly reduced compared to what one would expect based on the dipoles associated with the adsorption of a single molecule [149].

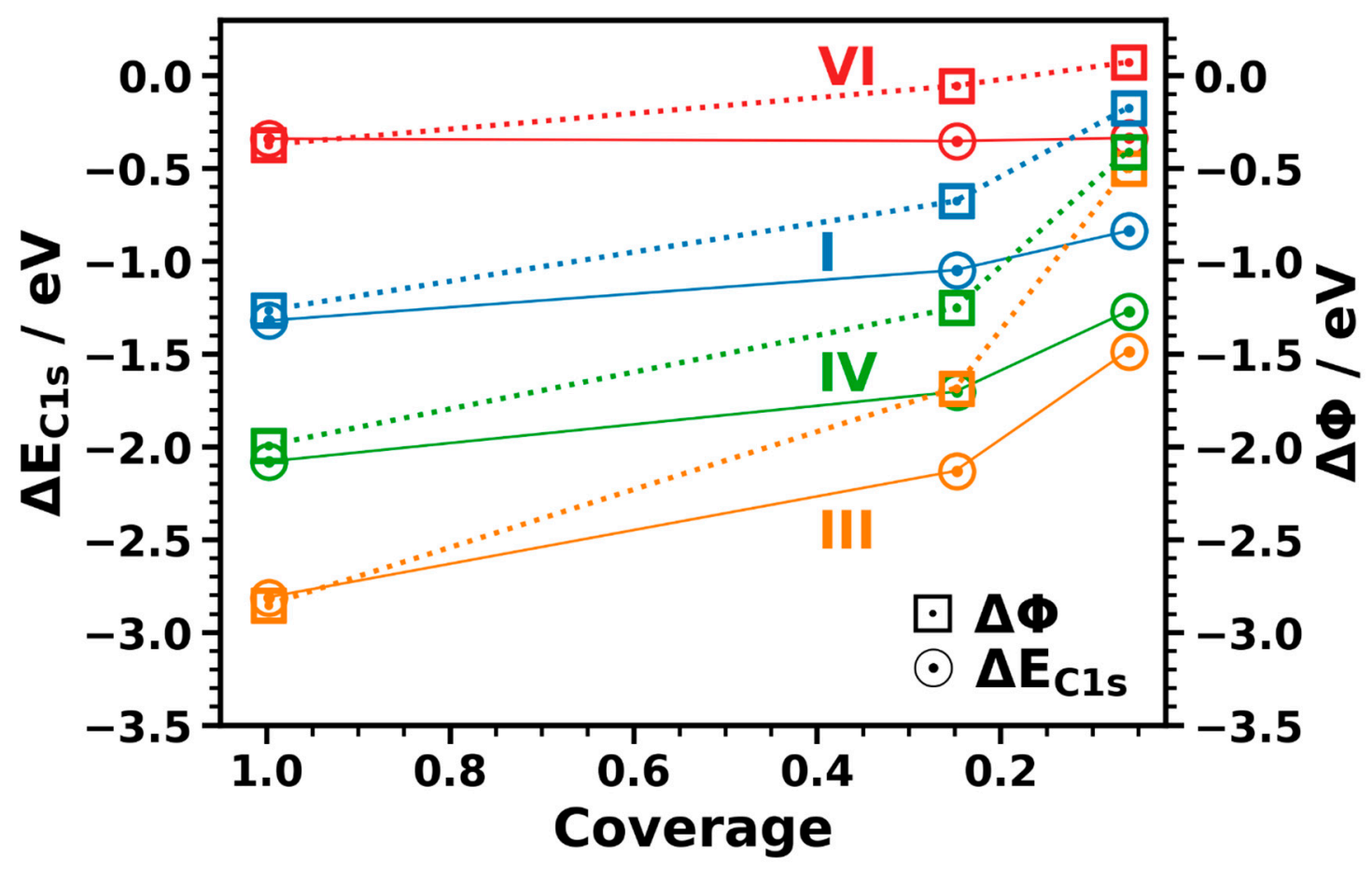

Figure 6. Core level shift, $\Delta \mathrm{E}_{\mathrm{C} 1 \mathrm{~s}}$, (circles) and work function change $\Delta \Phi$ (square symbols) for systems I, III, IV, and VI as a function of coverage (varied between full, a quarter, and 1/16 coverage, where the latter approaches the single molecule limit, see Supplementary Materials). All energies are reported relative to the values of the non-interacting reference system VIa.

Another observation in Figure 6 is that the coverage-dependence of the core level binding energies (circles and solid line) is much weaker than that of $\Delta \Phi$ (squares and dotted line). This is particularly obvious for system VI, for which there is almost no change of $\Delta \mathrm{E}_{\mathrm{C} 1 \mathrm{~s}}$ with coverage, while the work function still changes by $0.5 \mathrm{eV}$. Qualitatively, the behavior is, however, the same for all studied systems, as shown in Figure 7 . There, one sees that the energy range covered by the $\Delta \Phi$ values is significantly larger than that for $\Delta \mathrm{E}_{\mathrm{C} 1 \mathrm{~s}}$. As a result, the slope of the linear fit to the dependence of $\Delta \Phi$ on $\Delta \mathrm{E}_{\mathrm{C} 1 \mathrm{~s}}$ (black lines in Figure 7) significantly decreases with decreasing coverage.

The main consequence of this observation is that at low dipole densities (in contrast to the full-coverage case, see above) $\Delta \mathrm{E}_{\mathrm{C} 1 \mathrm{~s}}$ is no longer a direct measure for the interface dipole. This can be explained by the different degrees of locality with which $\Delta \Phi$ and $\Delta \mathrm{E}_{\mathrm{C} 1 \mathrm{~s}}$ probe the electronic structure of the interface $[48,148,150]$. The value of $\Delta \Phi$ is determined by the energy difference between the Fermi level and the vacuum level far above the surface, i.e., in the far field. Conversely, core level binding energies probe the electrostatic energy in the immediate vicinity of the atom whose core electron is excited [48]. The latter is comparably close to the interface dipole at the bond between the molecule and the substrate. Thus, the shift in the electrostatic energy due to the dipole is still relevant, even if it is strongly reduced due to the drop of the shift with the inverse of the third power of the distance between atom and dipole. This is illustrated in Figure 8, where we show the change in electrostatic 
energy due to the formation of the bond between the pyridine-docked SAM and the metal substrate. Consequently, Figure 8 does not actually reflect the impact of the entire interface dipole, but only of the part resulting from the bond dipole. This quantity can, however, be calculated conveniently by subtracting the electrostatic energies of the subsystems from that of the bonded interface, which is not possible for the full interface dipole. It is also well suited to qualitatively illustrate the difference between the local and the far-field situation, even if one cannot expect quantitative agreement with the data from Figures 6 and 7, which are still determined by the entire interface dipole. For the full coverage system in the bottom panel of Figure 8, the main drop in electrostatic energy occurs at the immediate metal-pyridine interface and the electrostatic energy in the region of the top ring is essentially the same as far above the sample (despite a minor potential variation at the distance of the topmost $\mathrm{C}-\mathrm{H}$ bond). Conversely, at 1/16 coverage the far-field electrostatic energy far above the interface (relevant for the work function) is several tenths of an $\mathrm{eV}$ higher than in the region of the upper carbon atoms (determining the position of the XPS peak).

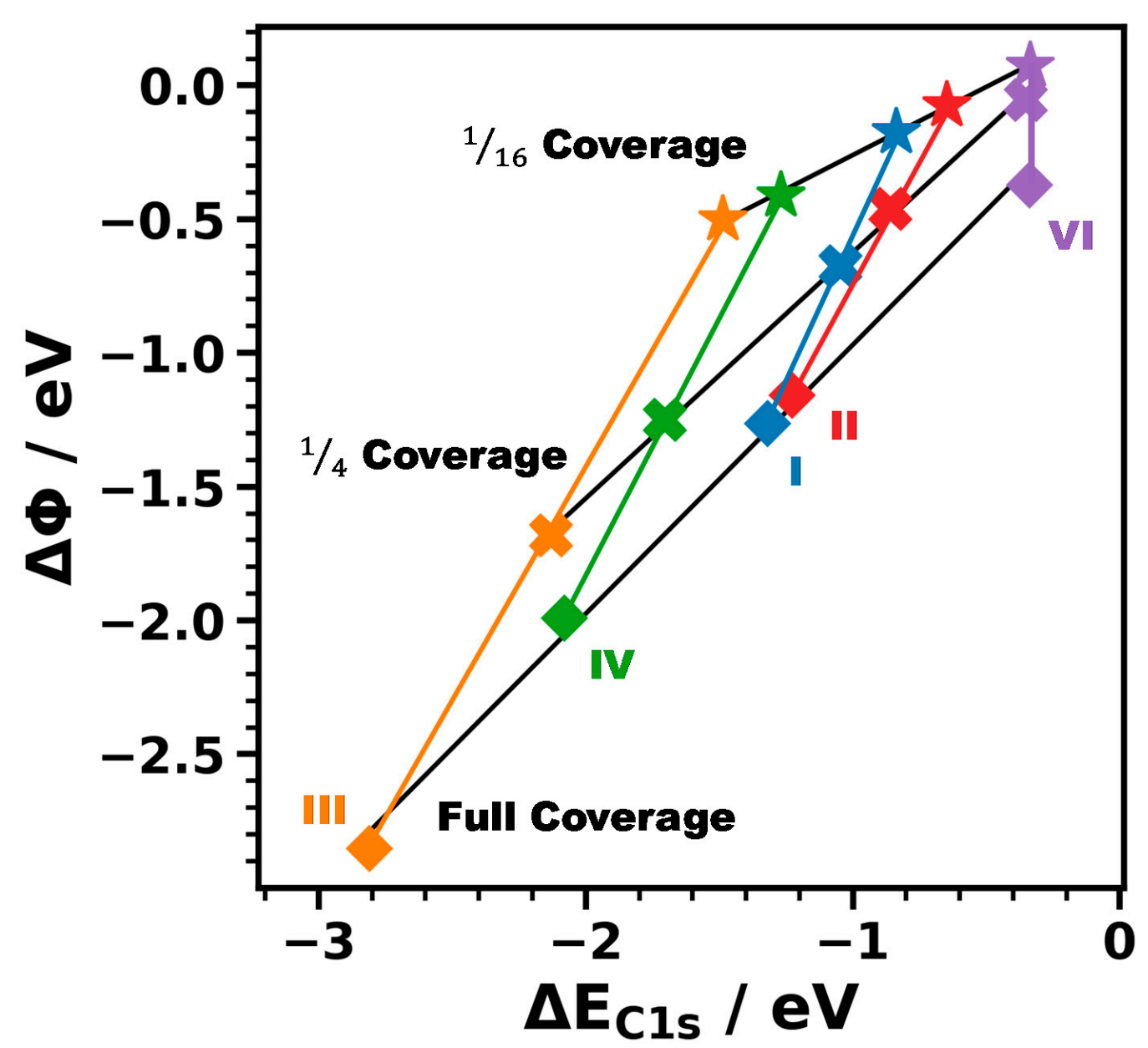

Figure 7. Core level shift, $\Delta \mathrm{E}_{\mathrm{C} 1 \mathrm{~s}}$, as a function of the work function change, $\Delta \Phi$, for system I (blue), system II (red), system III (orange), system IV (green), and system VI (violet). Results for full, 1/4, and $1 / 16$ coverage are compared. The black lines are fits to all systems for specific coverages, while the colored lines were fitted to the coverage-dependence for a specific system. 


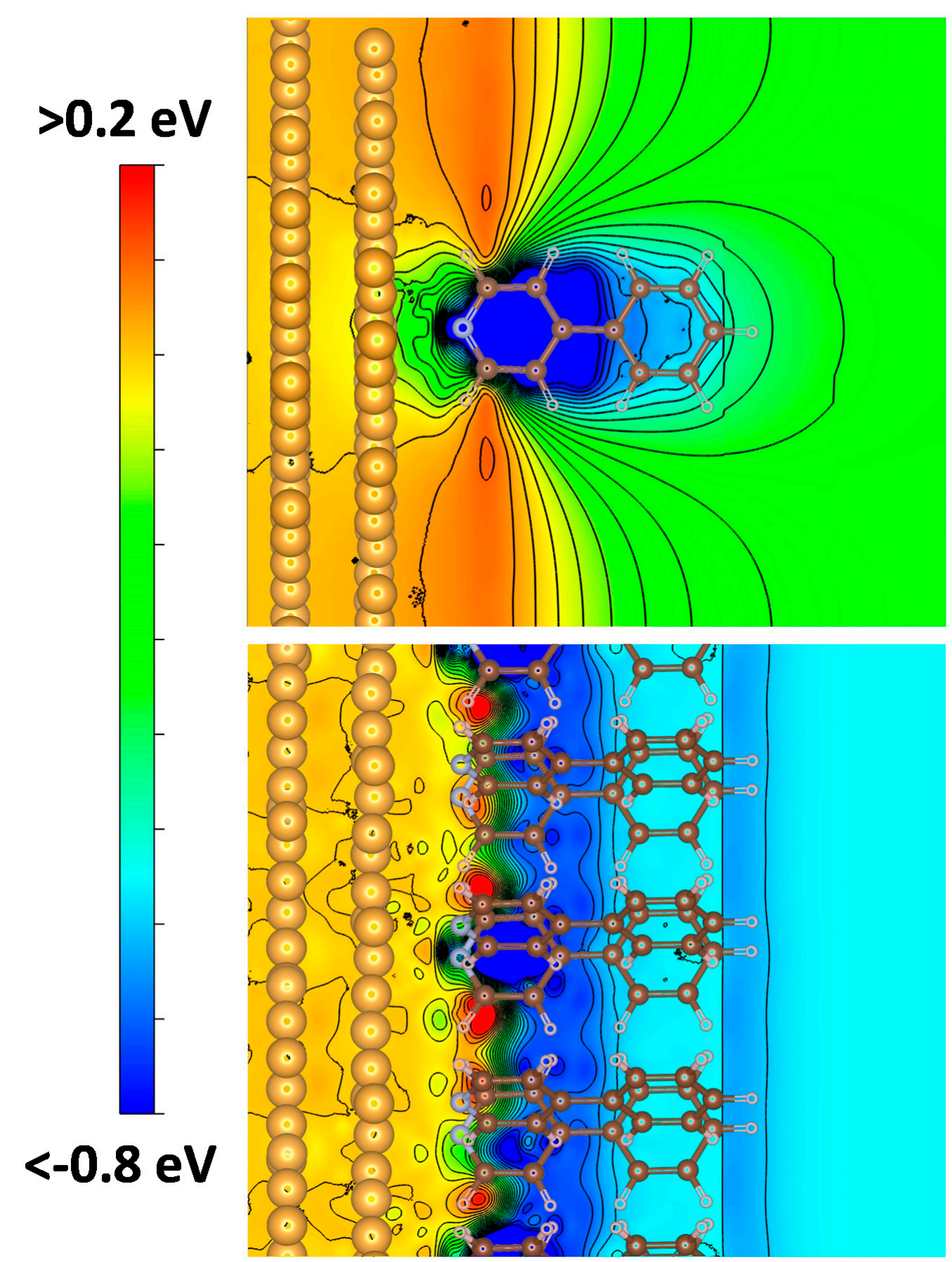

Figure 8. Contour plot of the change in the electrostatic energy due to metal-SAM bonding, i.e., due to the bond dipole (as part of the interface dipole) for system III. The potential is plotted for a plane defined by the plane of one of the molecules in the unit cell (see Supplementary Materials). The top (bottom) panel contains the result for $1 / 16$ (full) coverage. Isolines are shown in steps of $0.05 \mathrm{eV}$.

\subsubsection{The Role of Structural Imperfections of the Interface}

For all systems we assumed perfectly ordered structures, which is triggered by the fact that especially for thiol-bonded SAMs highly ordered monolayers can be routinely obtained in carefully performed experiments. Still, in the following the possible consequences of deviations from perfect interfaces shall be briefly summarized: reduced dipole densities diminish the observed shifts, as can be inferred from the description in Section 3.1 and as discussed explicitly in Section 3.3.3. This also applies, 
when disorder reduces the net dipole per docking group perpendicular to the surface, i.e., although the shifts discussed in Section 3.3.1 are comparably large, for imperfect samples high-resolution measurements will be necessary. In passing we note that lateral inhomogeneities of the dipole density can result in a significant broadening of the spectra and in extreme cases even in the occurrence of multiple peaks, as we showed for mixed monolayers of embedded-dipole SAMs [48]. This is a consequence of XPS probing the local electrostatic potential at the atom from which the electron is excited. Similar considerations would apply to substrates with laterally inhomogeneous local work functions. Finally, it should be noted that the actually measured electrostatic shifts are determined by the "true" interface dipoles, where contaminants at the interface, e.g., for ex-situ prepared samples (or also the presence of ad atoms) can change the situation compared to the model case assumed in simulations. When dealing with strongly bonded adsorbates, like thiolates, one, however, is in the fortunate situation that their bonding to noble metal substrates typically displaces contaminants, which also explains, why for the XPS simulations on model systems mentioned in the introduction section, we typically obtained a favorable agreement with experiments on ex-situ prepared samples $[22,48,49,63,64,90]$.

\section{Conclusions}

In the present contribution it is shown that X-ray photoelectron spectroscopy is a suitable tool for determining interface dipoles in densely packed self-assembled monolayers. This is shown via simulations on a number of biphenyl-based monolayers bonded to an $\mathrm{Au}(111)$ substrate by a broad range of different docking groups. The varying interface dipoles in these systems result in shifts of the core level binding energies by more than $1 \mathrm{eV}$, concomitantly shifting also the associated XP spectra. For SAMs not bearing polar tail groups the electrostatically triggered core level shifts directly correlate with SAM-induced work function changes. This correlation is broken, when work functions are further modified by polar tail group substituents. Nevertheless, even in these cases the XP spectra are a direct measure for the interface dipoles. The situation changes, when the dipole density at the interface is reduced. Then core level binding energies are still determined by the local electrostatic energy at the atoms from which the photoelectrons are excited. This energy is, however, no longer directly representative of the magnitude of the interface dipole, as it is strongly influenced, for example, by the distance of the excited atom from the location of the dipole. As a result, also the direct equivalence between core level shifts and work function changes is lost at reduced coverages, even though XPS still is suited for probing the local electrostatic energy (at least as long as chemical shifts, e.g., due to interfacial charge transfer are not superimposed on the electrostatic ones).

Supplementary Materials: Additional information on the computational methodology, a flow-chart summarizing the computational procedure, additional computational results, and views of unit cells and supercells are available online at http://www.mdpi.com/2076-3417/10/17/5735/s1.

Author Contributions: T.C.T. has performed all calculations, analyzed the results, compiled most figures, and wrote a first draft of the manuscript. E.Z. guided and supervised the research, contributed to the analysis of the data, compiled Figure 1, and revised the manuscript. All authors have read and agreed to the published version of the manuscript.

Funding: This work was funded (including the open access funding) by the Austrian Science Fund (FWF): P28051-N36. The quantum mechanical calculations have been performed using the Vienna Scientific Cluster (VSC3).

Conflicts of Interest: The authors declare no conflict of interest.

\section{References}

1. Casalini, S.; Bortolotti, C.A.; Leonardi, F.; Biscarini, F. Self-assembled monolayers in organic electronics. Chem. Soc. Rev. 2017, 46, 40-71. [CrossRef] [PubMed]

2. Halik, M.; Hirsch, A. The Potential of Molecular Self-Assembled Monolayers in Organic Electronic Devices. Adv. Mater. 2011, 23, 2689-2695. [CrossRef] [PubMed]

3. Chua, L.L.; Zaumseil, J.; Chang, J.F.; Ou, E.C.W.; Ho, P.K.H.; Sirringhaus, H.; Friend, R.H. General observation of n-type field-effect behaviour in organic semiconductors. Nature 2005, 434, 194-199. [CrossRef] [PubMed] 
4. Kobayashi, S.; Nishikawa, T.; Takenobu, T.; Mori, S.; Shimoda, T.; Mitani, T.; Shimotani, H.; Yoshimoto, N.; Ogawa, S.; Iwasa, Y. Control of carrier density by self-assembled monolayers in organic field-effect transistors. Nat. Mater. 2004, 3, 317-322. [CrossRef]

5. Pernstich, K.P.; Haas, S.; Oberhoff, D.; Goldmann, C.; Gundlach, D.J.; Batlogg, B.; Rashid, A.N.; Schitter, G. Threshold voltage shift in organic field effect transistors by dipole monolayers on the gate insulator. J. Appl. Phys. 2004, 96, 6431-6438. [CrossRef]

6. Pacher, P.; Lex, A.; Proschek, V.; Etschmaier, H.; Tchernychova, E.; Sezen, M.; Scherf, U.; Grogger, W.; Trimmel, G.; Slugovc, C.; et al. Chemical Control of Local Doping in Organic Thin-Film Transistors: From Depletion to Enhancement. Adv. Mater. 2008, 20, 3143-3148. [CrossRef]

7. Aghamohammadi, M.; Rödel, R.; Zschieschang, U.; Ocal, C.; Boschker, H.; Weitz, R.T.; Barrena, E.; Klauk, H. Threshold-Voltage Shifts in Organic Transistors Due to Self-Assembled Monolayers at the Dielectric: Evidence for Electronic Coupling and Dipolar Effects. ACS Appl. Mater. Interfaces 2015, 7, 22775-22785. [CrossRef]

8. Campbell, I.H.; Rubin, S.; Zawodzinski, T.A.; Kress, J.D.; Martin, R.L.; Smith, D.L.; Barashkov, N.N.; Ferraris, J.P. Controlling Schottky energy barriers in organic electronic devices using self-assembled monolayers. Phys. Rev. B 1996, 54, R14321-R14324. [CrossRef]

9. Campbell, I.H.; Kress, J.D.; Martin, R.L.; Smith, D.L.; Barashkov, N.N.; Ferraris, J.P. Controlling charge injection in organic electronic devices using self-assembled monolayers. Appl. Phys. Lett. 1997, 71, 3528-3530. [CrossRef]

10. Yan, H.; Huang, Q.; Cui, J.; Veinot, J.G.C.; Kern, M.M.; Marks, T.J. High-Brightness Blue Light-Emitting Polymer Diodes via Anode Modification Using a Self-Assembled Monolayer. Adv. Mater. 2003, 15, 835-838. [CrossRef]

11. De Boer, B.; Hadipour, A.; Mandoc, M.M.; van Woudenbergh, T.; Blom, P.W.M. Tuning of Metal Work Functions with Self-Assembled Monolayers. Adv. Mater. 2005, 17, 621-625. [CrossRef]

12. Jang, Y.; Cho, J.H.; Kim, D.H.; Park, Y.D.; Hwang, M.; Cho, K. Effects of the permanent dipoles of self-assembled monolayer-treated insulator surfaces on the field-effect mobility of a pentacene thin-film transistor. Appl. Phys. Lett. 2007, 90, 132104. [CrossRef]

13. Kitamura, M.; Kuzumoto, Y.; Kang, W.; Aomori, S.; Arakawa, Y. High conductance bottom-contact pentacene thin-film transistors with gold-nickel adhesion layers. Appl. Phys. Lett. 2010, 97, 033306. [CrossRef]

14. Schulz, P.; Schäfer, T.; Zangmeister, C.D.; Effertz, C.; Meyer, D.; Mokros, D.; van Zee, R.D.; Mazzarello, R.; Wuttig, M. A New Route to Low Resistance Contacts for Performance-Enhanced Organic Electronic Devices. Adv. Mater. Interfaces 2014, 1, 1300130. [CrossRef]

15. Kim, J.; Rim, Y.S.; Liu, Y.; Serino, A.C.; Thomas, J.C.; Chen, H.; Yang, Y.; Weiss, P.S. Interface Control in Organic Electronics Using Mixed Monolayers of Carboranethiol Isomers. Nano Lett. 2014, 14, $2946-2951$. [CrossRef]

16. Fenwick, O.; Van Dyck, C.; Murugavel, K.; Cornil, D.; Reinders, F.; Haar, S.; Mayor, M.; Cornil, J.; Samorì, P. Modulating the charge injection in organic field-effect transistors: Fluorinated oligophenyl self-assembled monolayers for high work function electrodes. J. Mater. Chem. C 2015, 3, 3007-3015. [CrossRef]

17. Petritz, A.; Krammer, M.; Sauter, E.; Gärtner, M.; Nascimbeni, G.; Schrode, B.; Fian, A.; Gold, H.; Cojocaru, A.; Karner-Petritz, E.; et al. Embedded Dipole Self-Assembled Monolayers for Contact Resistance Tuning in p-Type and n-Type Organic Thin Film Transistors and Flexible Electronic Circuits. Adv. Funct. Mater. 2018, 28, 1804462. [CrossRef]

18. Borchert, J.W.; Peng, B.; Letzkus, F.; Burghartz, J.N.; Chan, P.K.L.; Zojer, K.; Ludwigs, S.; Klauk, H. Small contact resistance and high-frequency operation of flexible low-voltage inverted coplanar organic transistors. Nat. Commun. 2019, 10. [CrossRef]

19. Evans, S.D.; Urankar, E.; Ulman, A.; Ferris, N. Self-assembled monolayers of alkanethiols containing a polar aromatic group: Effects of the dipole position on molecular packing, orientation, and surface wetting properties. J. Am. Chem. Soc. 1991, 113, 4121-4131. [CrossRef]

20. Cabarcos, O.M.; Shaporenko, A.; Weidner, T.; Uppili, S.; Dake, L.S.; Zharnikov, M.; Allara, D.L. Physical and Electronic Structure Effects of Embedded Dipoles in Self-Assembled Monolayers: Characterization of Mid-Chain Ester Functionalized Alkanethiols on Au\{111\}. J. Phys. Chem. C 2008, 112, 10842-10854. [CrossRef] 
21. Abu-Husein, T.; Schuster, S.; Egger, D.A.; Kind, M.; Santowski, T.; Wiesner, A.; Chiechi, R.; Zojer, E.; Terfort, A.; Zharnikov, M. The Effects of Embedded Dipoles in Aromatic Self-Assembled Monolayers. Adv. Funct. Mater. 2015, 25, 3943-3957. [CrossRef]

22. Gärtner, M.; Sauter, E.; Nascimbeni, G.; Wiesner, A.; Kind, M.; Werner, P.; Schuch, C.; Abu-Husein, T.; Asyuda, A.; Bats, J.W.; et al. Self-Assembled Monolayers with Distributed Dipole Moments Originating from Bipyrimidine Units. J. Phys. Chem. C 2020, 124, 504-519. [CrossRef]

23. Baghbanzadeh, M.; Belding, L.; Yuan, L.; Park, J.; Al-Sayah, M.H.; Bowers, C.M.; Whitesides, G.M. Dipole-Induced Rectification Across $\mathrm{Ag}^{\mathrm{TS}} / \mathrm{SAM} / / \mathrm{Ga}_{2} \mathrm{O}_{3} /$ EGaIn Junctions. J. Am. Chem. Soc. 2019, 141, 8969-8980. [CrossRef] [PubMed]

24. Kang, J.F.; Ulman, A.; Liao, S.; Jordan, R. Mixed Self-Assembled Monolayers of Highly Polar Rigid Biphenyl Thiols. Langmuir 1999, 15, 2095-2098. [CrossRef]

25. Zehner, R.W.; Parsons, B.F.; Hsung, R.P.; Sita, L.R. Tuning the Work Function of Gold with Self-Assembled Monolayers Derived from $\mathrm{X}-\left[\mathrm{C}_{6} \mathrm{H}_{4}-\mathrm{C}: \mathrm{C}-\right]_{n} \mathrm{C}_{6} \mathrm{H}_{4}-\mathrm{SH}\left(n=0,1,2 ; \mathrm{X}=\mathrm{H}, \mathrm{F}, \mathrm{CH}_{3}, \mathrm{CF}_{3}\right.$, and $\left.\mathrm{OCH}_{3}\right)$. Langmuir 1999, 15, 1121-1127. [CrossRef]

26. Ganzorig, C.; Kwak, K.J.; Yagi, K.; Fujihira, M. Fine tuning work function of indium tin oxide by surface molecular design: Enhanced hole injection in organic electroluminescent devices. Appl. Phys. Lett. 2001, 79, 272-274. [CrossRef]

27. Heimel, G.; Romaner, L.; Brédas, J.-L.; Zojer, E. Interface Energetics and Level Alignment at Covalent Metal-Molecule Junctions: $\pi$-Conjugated Thiols on Gold. Phys. Rev. Lett. 2006, 96. [CrossRef]

28. Sun, Q.; Selloni, A. Interface and Molecular Electronic Structure vs Tunneling Characteristics of $\mathrm{CH}_{3}-$ and $\mathrm{CF}_{3}$-Terminated Thiol Monolayers on Au(111). J. Phys. Chem. A 2006, 110, 11396-11400. [CrossRef]

29. Yip, H.L.; Hau, S.K.; Baek, N.S.; Ma, H.; Jen, A.K.Y. Polymer Solar Cells That Use Self-Assembled-Monolayer-Modified ZnO/Metals as Cathodes. Adv. Mater. 2008, 20, 2376-2382. [CrossRef]

30. Demirkan, K.; Mathew, A.; Weiland, C.; Yao, Y.; Rawlett, A.M.; Tour, J.M.; Opila, R.L. Energy level alignment at organic semiconductor/metal interfaces: Effect of polar self-assembled monolayers at the interface. J. Chem. Phys. 2008, 128, 074705. [CrossRef]

31. Heimel, G.; Romaner, L.; Zojer, E.; Bredas, J.L. The Interface Energetics of Self-Assembled Monolayers on Metals. Acc. Chem. Res. 2008, 41, 721-729. [CrossRef] [PubMed]

32. Malicki, M.; Guan, Z.; Ha, S.D.; Heimel, G.; Barlow, S.; Rumi, M.; Kahn, A.; Marder, S.R. Preparation and Characterization of $4^{\prime}$-Donor Substituted Stilbene-4-thiolate Monolayers and Their Influence on the Work Function of Gold. Langmuir 2009, 25, 7967-7975. [CrossRef] [PubMed]

33. Yoon, H.J.; Bowers, C.M.; Baghbanzadeh, M.; Whitesides, G.M. The Rate of Charge Tunneling Is Insensitive to Polar Terminal Groups in Self-Assembled Monolayers in $\mathrm{Ag}^{\mathrm{TS}} \mathrm{S}\left(\mathrm{CH}_{2}\right)_{n} \mathrm{M}\left(\mathrm{CH}_{2}\right)_{m} \mathrm{~T} / / \mathrm{Ga}_{2} \mathrm{O}_{3} / \mathrm{EGaIn}$ Junctions. J. Am. Chem. Soc. 2014, 136, 16-19. [CrossRef] [PubMed]

34. Lee, H.J.; Jamison, A.C.; Lee, T.R. Surface Dipoles: A Growing Body of Evidence Supports Their Impact and Importance. Acc. Chem. Res. 2015, 48, 3007-3015. [CrossRef]

35. Vilan, A.; Cahen, D. Chemical Modification of Semiconductor Surfaces for Molecular Electronics. Chem. Rev. 2017, 117, 4624-4666. [CrossRef]

36. Lindell, L.; Vahlberg, C.; Uvdal, K.; Fahlman, M.; Braun, S. Self-assembled monolayer engineered interfaces: Energy level alignment tuning through chain length and end-group polarity. J. Electron Spectrosc. Relat. Phenom. 2015, 204, 140-144. [CrossRef]

37. MacLeod, B.A.; Horwitz, N.E.; Ratcliff, E.L.; Jenkins, J.L.; Armstrong, N.R.; Giordano, A.J.; Hotchkiss, P.J.; Marder, S.R.; Campbell, C.T.; Ginger, D.S. Built-In Potential in Conjugated Polymer Diodes with Changing Anode Work Function: Interfacial States and Deviation from the Schottky-Mott Limit. J. Phys. Chem. Lett. 2012, 3, 1202-1207. [CrossRef]

38. Schmidt, C.; Witt, A.; Witte, G. Tailoring the $\mathrm{Cu}(100)$ Work Function by Substituted Benzenethiolate Self-Assembled Monolayers. J. Phys. Chem. A 2011, 115, 7234-7241. [CrossRef]

39. Heimel, G.; Romaner, L.; Zojer, E.; Brédas, J.L. Toward Control of the Metal-Organic Interfacial Electronic Structure in Molecular Electronics: A First-Principles Study on Self-Assembled Monolayers of $\pi$-Conjugated Molecules on Noble Metals. Nano Lett. 2007, 7, 932-940. [CrossRef]

40. Natan, A.; Kronik, L.; Haick, H.; Tung, R.T. Electrostatic Properties of Ideal and Non-ideal Polar Organic Monolayers: Implications for Electronic Devices. Adv. Mater. 2007, 19, 4103-4117. [CrossRef] 
41. Wang, L.; Rangger, G.M.; Ma, Z.; Li, Q.; Shuai, Z.; Zojer, E.; Heimel, G. Is there a Au-S bond dipole in self-assembled monolayers on gold? Phys. Chem. Chem. Phys. 2010, 12, 4287-4290. [CrossRef] [PubMed]

42. Zojer, E.; Taucher, T.C.; Hofmann, O.T. The Impact of Dipolar Layers on the Electronic Properties of Organic/Inorganic Hybrid Interfaces. Adv. Mater. Interfaces 2019, 6, 1900581. [CrossRef]

43. Alloway, D.M.; Hofmann, M.; Smith, D.L.; Gruhn, N.E.; Graham, A.L.; Colorado, R.; Wysocki, V.H.; Lee, T.R.; Lee, P.A.; Armstrong, N.R. Interface Dipoles Arising from Self-Assembled Monolayers on Gold: UV-Photoemission Studies of Alkanethiols and Partially Fluorinated Alkanethiols. J. Phys. Chem. B 2003, 107, 11690-11699. [CrossRef]

44. Rusu, P.C.; Brocks, G. Surface Dipoles and Work Functions of Alkylthiolates and Fluorinated Alkylthiolates on $\mathrm{Au}(111)$. J. Phys. Chem. B 2006, 110, 22628-22634. [CrossRef]

45. Cahen, D.; Naaman, R.; Vager, Z. The Cooperative Molecular Field Effect. Adv. Funct. Mater. 2005, 15, 1571-1578. [CrossRef]

46. Monti, O.L.A. Understanding Interfacial Electronic Structure and Charge Transfer: An Electrostatic Perspective. J. Phys. Chem. Lett. 2012, 3, 2342-2351. [CrossRef]

47. Ishii, H.; Sugiyama, K.; Ito, E.; Seki, K. Energy Level Alignment and Interfacial Electronic Structures at Organic/Metal and Organic/Organic Interfaces. Adv. Mater. 1999, 11, 605-625. [CrossRef]

48. Hehn, I.; Schuster, S.; Wächter, T.; Abu-Husein, T.; Terfort, A.; Zharnikov, M.; Zojer, E. Employing X-ray Photoelectron Spectroscopy for Determining Layer Homogeneity in Mixed Polar Self-Assembled Monolayers. J. Phys. Chem. Lett. 2016, 7, 2994-3000. [CrossRef]

49. Gärtner, M.; Sauter, E.; Nascimbeni, G.; Petritz, A.; Wiesner, A.; Kind, M.; Abu-Husein, T.; Bolte, M.; Stadlober, B.; Zojer, E.; et al. Understanding the Properties of Tailor-Made Self-Assembled Monolayers with Embedded Dipole Moments for Interface Engineering. J. Phys. Chem. C 2018, 122, 28757-28774. [CrossRef]

50. Braun, S.; Salaneck, W.R.; Fahlman, M. Energy-Level Alignment at Organic/Metal and Organic/Organic Interfaces. Adv. Mater. 2009, 21, 1450-1472. [CrossRef]

51. Venkataraman, N.V.; Zürcher, S.; Rossi, A.; Lee, S.; Naujoks, N.; Spencer, N.D. Spatial Tuning of the Metal Work Function by Means of Alkanethiol and Fluorinated Alkanethiol Gradients. J. Phys. Chem. C 2009, 113, 5620-5628. [CrossRef]

52. Lange, I.; Reiter, S.; Pätzel, M.; Zykov, A.; Nefedov, A.; Hildebrandt, J.; Hecht, S.; Kowarik, S.; Wöll, C.; Heimel, G.; et al. Tuning the Work Function of Polar Zinc Oxide Surfaces using Modified Phosphonic Acid Self-Assembled Monolayers. Adv. Funct. Mater. 2014, 24, 7014-7024. [CrossRef]

53. Kim, B.; Choi, S.H.; Zhu, X.-Y.; Frisbie, C.D. Molecular Tunnel Junctions Based on $\pi$-Conjugated Oligoacene Thiols and Dithiols between Ag, Au, and Pt Contacts: Effect of Surface Linking Group and Metal Work Function. J. Am. Chem. Soc. 2011, 133, 19864-19877. [CrossRef] [PubMed]

54. Kim, T.; Darancet, P.; Widawsky, J.R.; Kotiuga, M.; Quek, S.Y.; Neaton, J.B.; Venkataraman, L. Determination of Energy Level Alignment and Coupling Strength in 4,4'-Bipyridine Single-Molecule Junctions. Nano Lett. 2014, 14, 794-798. [CrossRef]

55. Egger, D.A.; Rissner, F.; Zojer, E.; Heimel, G. Polarity Switching of Charge Transport and Thermoelectricity in Self-Assembled Monolayer Devices. Adv. Mater. 2012, 24, 4403-4407. [CrossRef]

56. Egger, D.A.; Liu, Z.F.; Neaton, J.B.; Kronik, L. Reliable Energy Level Alignment at Physisorbed Molecule-Metal Interfaces from Density Functional Theory. Nano Lett. 2015, 15, 2448-2455. [CrossRef]

57. Obersteiner, V.; Egger, D.A.; Heimel, G.; Zojer, E. Impact of Collective Electrostatic Effects on Charge Transport through Molecular Monolayers. J. Phys. Chem. C 2014, 118, 22395-22401. [CrossRef]

58. Obersteiner, V.; Huhs, G.; Papior, N.; Zojer, E. Unconventional Current Scaling and Edge Effects for Charge Transport through Molecular Clusters. Nano Lett. 2017, 17, 7350-7357. [CrossRef]

59. Xie, Z.; Bâldea, I.; Smith, C.E.; Wu, Y.; Frisbie, C.D. Experimental and Theoretical Analysis of Nanotransport in Oligophenylene Dithiol Junctions as a Function of Molecular Length and Contact Work Function. ACS Nano 2015, 9, 8022-8036. [CrossRef]

60. Xie, Z.; Bâldea, I.; Frisbie, C.D. Determination of Energy-Level Alignment in Molecular Tunnel Junctions by Transport and Spectroscopy: Self-Consistency for the Case of Oligophenylene Thiols and Dithiols on Ag, Au, and Pt Electrodes. J. Am. Chem. Soc. 2019, 141, 3670-3681. [CrossRef]

61. Xie, Z.; Bâldea, I.; Frisbie, C.D. Energy Level Alignment in Molecular Tunnel Junctions by Transport and Spectroscopy: Self-Consistency for the Case of Alkyl Thiols and Dithiols on Ag, Au, and Pt Electrodes. J. Am. Chem. Soc. 2019, 141, 18182-18192. [CrossRef] [PubMed] 
62. Vilan, A.; Aswal, D.; Cahen, D. Large-Area, Ensemble Molecular Electronics: Motivation and Challenges. Chem. Rev. 2017, 117, 4248-4286. [CrossRef] [PubMed]

63. Taucher, T.C.; Hehn, I.; Hofmann, O.T.; Zharnikov, M.; Zojer, E. Understanding Chemical versus Electrostatic Shifts in X-ray Photoelectron Spectra of Organic Self-Assembled Monolayers. J. Phys. Chem. C 2016, 120, 3428-3437. [CrossRef] [PubMed]

64. Cabarcos, O.M.; Schuster, S.; Hehn, I.; Zhang, P.P.; Maitani, M.M.; Sullivan, N.; Giguère, J.-B.; Morin, J.-F.; Weiss, P.S.; Zojer, E.; et al. Effects of Embedded Dipole Layers on Electrostatic Properties of Alkanethiolate Self-Assembled Monolayers. J. Phys. Chem. C 2017, 121, 15815-15830. [CrossRef]

65. El-Sayed, A.; Borghetti, P.; Goiri, E.; Rogero, C.; Floreano, L.; Lovat, G.; Mowbray, D.J.; Cabellos, J.L.; Wakayama, Y.; Rubio, A.; et al. Understanding Energy-Level Alignment in Donor-Acceptor/Metal Interfaces from Core-Level Shifts. ACS Nano 2013, 7, 6914-6920. [CrossRef]

66. Siegbahn, K. (Ed.) ESCA. Atomic, Molecular and Solid State Structure Studied by Means of Electron Spectroscopy; Nova Acta Regiae Societatis Scientiarum Upsaliensis; Uppsala Almqvist \& Wiksell: Stockholm, Sweden, 1967; Volume 20, Ser. 4.

67. Benesh, G.A.; King, D.A. Core-level shift spectroscopy for adsorbates: Ionic, covalent or metallic bonding? Chem. Phys. Lett. 1992, 191, 315-319. [CrossRef]

68. Bagus, P.S.; Ilton, E.S.; Nelin, C.J. The interpretation of XPS spectra: Insights into materials properties. Surf. Sci. Rep. 2013, 68, 273-304. [CrossRef]

69. Bagus, P.S.; Ilton, E.; Nelin, C.J. Extracting Chemical Information from XPS Spectra: A Perspective. Catal. Lett. 2018, 148, 1785-1802. [CrossRef]

70. Kirchhuebel, T.; Monti, O.L.A.; Munakata, T.; Kera, S.; Forker, R.; Fritz, T. The role of initial and final states in molecular spectroscopies. Phys. Chem. Chem. Phys. 2019, 21, 12730-12747. [CrossRef]

71. Ulman, A. Formation and Structure of Self-Assembled Monolayers. Chem. Rev. 1996, 96, $1533-1554$. [CrossRef]

72. Schreiber, F. Structure and growth of self-assembling monolayers. Prog. Surf. Sci. 2000, 65, 151-257. [CrossRef]

73. Heister, K.; Zharnikov, M.; Grunze, M.; Johansson, L.S.O. Adsorption of Alkanethiols and Biphenylthiols on Au and Ag Substrates: A High-Resolution X-ray Photoelectron Spectroscopy Study. J. Phys. Chem. B 2001, 105, 4058-4061. [CrossRef]

74. Love, J.C.; Estroff, L.A.; Kriebel, J.K.; Nuzzo, R.G.; Whitesides, G.M. Self-Assembled Monolayers of Thiolates on Metals as a Form of Nanotechnology. Chem. Rev. 2005, 105, 1103-1170. [CrossRef]

75. Shaporenko, A.; Cyganik, P.; Buck, M.; Terfort, A.; Zharnikov, M. Self-Assembled Monolayers of Aromatic Selenolates on Noble Metal Substrates. J. Phys. Chem. B 2005, 109, 13630-13638. [CrossRef] [PubMed]

76. Käfer, D.; Bashir, A.; Witte, G. Interplay of Anchoring and Ordering in Aromatic Self-Assembled Monolayers. J. Phys. Chem. C 2007, 111, 10546-10551. [CrossRef]

77. Merzlikin, S.V.; Tolkachev, N.N.; Strunskus, T.; Witte, G.; Glogowski, T.; Wöll, C.; Grünert, W. Resolving the depth coordinate in photoelectron spectroscopy-Comparison of excitation energy variation vs. angular-resolved XPS for the analysis of a self-assembled monolayer model system. Surf. Sci. 2008, 602, 755-767. [CrossRef]

78. Beccari, M.; Kanjilal, A.; Betti, M.G.; Mariani, C.; Floreano, L.; Cossaro, A.; Di Castro, V. Characterization of benzenethiolate self-assembled monolayer on $\mathrm{Cu}(100)$ by XPS and NEXAFS. J. Electron Spectrosc. Relat. Phenom. 2009, 172, 64-68. [CrossRef]

79. Vericat, C.; Vela, M.E.; Benitez, G.; Carro, P.; Salvarezza, R.C. Self-assembled monolayers of thiols and dithiols on gold: New challenges for a well-known system. Chem. Soc. Rev. 2010, 39, 1805. [CrossRef]

80. Zaba, T.; Noworolska, A.; Bowers, C.M.; Breiten, B.; Whitesides, G.M.; Cyganik, P. Formation of Highly Ordered Self-Assembled Monolayers of Alkynes on Au(111) Substrate. J. Am. Chem. Soc. 2014, 136, 11918-11921. [CrossRef]

81. Euti, E.M.; Vélez Romero, P.; Linarez Pérez, O.; Ruano, G.; Patrito, E.M.; Zampieri, G.; Leiva, E.P.M.; Macagno, V.A.; Cometto, F.P. Electrochemical, HR-XPS and SERS study of the self-assembly of biphenyl 4,4'-dithiol on $\mathrm{Au}(111)$ from solution phase. Surf. Sci. 2014, 630, 101-108. [CrossRef]

82. Ossowski, J.; Nascimbeni, G.; Żaba, T.; Verwüster, E.; Rysz, J.; Terfort, A.; Zharnikov, M.; Zojer, E.; Cyganik, P. Relative Thermal Stability of Thiolate- and Selenolate-Bonded Aromatic Monolayers on the Au(111) Substrate. J. Phys. Chem. C 2017, 121, 28031-28042. [CrossRef] 
83. Kang, J.F.; Liao, S.; Jordan, R.; Ulman, A. Mixed Self-assembled Monolayers of Rigid Biphenyl Thiols: Impact of Solvent and Dipole Moment. J. Am. Chem. Soc. 1998, 120, 9662-9667. [CrossRef]

84. Rong, H.T.; Frey, S.; Yang, Y.J.; Zharnikov, M.; Buck, M.; Wühn, M.; Wöll, C.; Helmchen, G. On the Importance of the Headgroup Substrate Bond in Thiol Monolayers: A Study of Biphenyl-Based Thiols on Gold and Silver. Langmuir 2001, 17, 1582-1593. [CrossRef]

85. Azzam, W.; Fuxen, C.; Birkner, A.; Rong, H.T.; Buck, M.; Wöll, C. Coexistence of Different Structural Phases in Thioaromatic Monolayers on Au(111). Langmuir 2003, 19, 4958-4968. [CrossRef]

86. Shaporenko, A.; Terfort, A.; Grunze, M.; Zharnikov, M. A detailed analysis of the photoemission spectra of basic thioaromatic monolayers on noble metal substrates. J. Electron Spectrosc. Relat. Phenom. 2006, 151, 45-51. [CrossRef]

87. Cyganik, P.; Buck, M.; Strunskus, T.; Shaporenko, A.; Wilton-Ely, J.D.E.T.; Zharnikov, M.; Wöll, C. Competition as a Design Concept: Polymorphism in Self-Assembled Monolayers of Biphenyl-Based Thiols. J. Am. Chem. Soc. 2006, 128, 13868-13878. [CrossRef]

88. Stoycheva, S.; Himmelhaus, M.; Fick, J.; Korniakov, A.; Grunze, M.; Ulman, A. Spectroscopic Characterization of $\omega$-Substituted Biphenylthiolates on Gold and Their Use as Substrates for "On-Top" Siloxane SAM Formation. Langmuir 2006, 22, 4170-4178. [CrossRef]

89. Krzykawska, A.; Ossowski, J.; Żaba, T.; Cyganik, P. Binding groups for highly ordered SAM formation: Carboxylic versus thiol. Chem. Commun. 2017, 53, 5748-5751. [CrossRef]

90. Sauter, E.; Nascimbeni, G.; Trefz, D.; Ludwigs, S.; Zojer, E.; von Wrochem, F.; Zharnikov, M. A dithiocarbamate anchoring group as a flexible platform for interface engineering. Phys. Chem. Chem. Phys. 2019, 21, 22511-22525. [CrossRef]

91. Blum, V.; Gehrke, R.; Hanke, F.; Havu, P.; Havu, V.; Ren, X.; Reuter, K.; Scheffler, M. Ab initio molecular simulations with numeric atom-centered orbitals. Comput. Phys. Commun. 2009, 180, 2175-2196. [CrossRef]

92. Havu, V.; Blum, V.; Havu, P.; Scheffler, M. Efficient integration for all-electron electronic structure calculation using numeric basis functions. J. Comput. Phys. 2009, 228, 8367-8379. [CrossRef]

93. Marek, A.; Blum, V.; Johanni, R.; Havu, V.; Lang, B.; Auckenthaler, T.; Heinecke, A.; Bungartz, H.-J.; Lederer, H. The ELPA library: Scalable parallel eigenvalue solutions for electronic structure theory and computational science. J. Phys. Condens. Matter 2014, 26, 213201. [CrossRef] [PubMed]

94. Togo, A.; Tanaka, I. Spglib: A software library for crystal symmetry search. arXiv 2018, arXiv:1808.01590.

95. Yu, V.W.; Corsetti, F.; García, A.; Huhn, W.P.; Jacquelin, M.; Jia, W.; Lange, B.; Lin, L.; Lu, J.; Mi, W.; et al. ELSI: A unified software interface for Kohn-Sham electronic structure solvers. Comput. Phys. Commun. 2018, 222, 267-285. [CrossRef]

96. Perdew, J.P.; Burke, K.; Ernzerhof, M. Generalized Gradient Approximation Made Simple. Phys. Rev. Lett. 1996, 77, 3865-3868. [CrossRef] [PubMed]

97. Perdew, J.P.; Burke, K.; Ernzerhof, M. ERRATA: Generalized Gradient Approximation Made Simple. Phys. Rev. Lett. 1997, 78, 1396. [CrossRef]

98. Ruiz, V.G.; Liu, W.; Zojer, E.; Scheffler, M.; Tkatchenko, A. Density-Functional Theory with Screened van der Waals Interactions for the Modeling of Hybrid Inorganic-Organic Systems. Phys. Rev. Lett. 2012, 108. [CrossRef]

99. Tkatchenko, A.; Scheffler, M. Accurate Molecular Van Der Waals Interactions from Ground-State Electron Density and Free-Atom Reference Data. Phys. Rev. Lett. 2009, 102. [CrossRef]

100. Neugebauer, J.; Scheffler, M. Adsorbate-substrate and adsorbate-adsorbate interactions of Na and K adlayers on Al(111). Phys. Rev. B 1992, 46, 16067-16080. [CrossRef]

101. Freysoldt, C.; Eggert, P.; Rinke, P.; Schindlmayr, A.; Scheffler, M. Screening in two dimensions: G W calculations for surfaces and thin films using the repeated-slab approach. Phys. Rev. B 2008, 77, 235428. [CrossRef]

102. Verwüster, E.; Hofmann, O.T.; Egger, D.A.; Zojer, E. Electronic Properties of Biphenylthiolates on Au(111): The Impact of Coverage Revisited. J. Phys. Chem. C 2015, 119, 7817-7825. [CrossRef]

103. Vackář, J.; Hyt’ha, M.; Šimůnek, A. All-electron pseudopotentials. Phys. Rev. B 1998, 58, 12712-12720. [CrossRef]

104. Methfessel, M.; Fiorentini, V.; Oppo, S. Connection between charge transfer and alloying core-level shifts based on density-functional calculations. Phys. Rev. B 2000, 61, 5229-5236. [CrossRef] 
105. Morikawa, Y.; Hayashi, T.; Liew, C.C.; Nozoye, H. First-principles theoretical study of alkylthiolate adsorption on $\mathrm{Au}$ (111). Surf. Sci. 2002, 507, 46-50. [CrossRef]

106. Heimel, G.; Romaner, L.; Brédas, J.L.; Zojer, E. Organic/metal interfaces in self-assembled monolayers of conjugated thiols: A first-principles benchmark study. Surf. Sci. 2006, 600, 4548-4562. [CrossRef]

107. Giesbers, M.; Marcelis, A.T.M.; Zuilhof, H. Simulation of XPS C1s Spectra of Organic Monolayers by Quantum Chemical Methods. Langmuir 2013, 29, 4782-4788. [CrossRef]

108. Pueyo Bellafont, N.; Illas, F.; Bagus, P.S. Validation of Koopmans' theorem for density functional theory binding energies. Phys. Chem. Chem. Phys. 2015, 17, 4015-4019. [CrossRef]

109. Ishiwari, F.; Nascimbeni, G.; Sauter, E.; Tago, H.; Shoji, Y.; Fujii, S.; Kiguchi, M.; Tada, T.; Zharnikov, M.; Zojer, E.; et al. Triptycene Tripods for the Formation of Highly Uniform and Densely Packed Self-Assembled Monolayers with Controlled Molecular Orientation. J. Am. Chem. Soc. 2019, 141, 5995-6005. [CrossRef]

110. Pueyo Bellafont, N.; Bagus, P.S.; Illas, F. Prediction of core level binding energies in density functional theory: Rigorous definition of initial and final state contributions and implications on the physical meaning of Kohn-Sham energies. J. Chem. Phys. 2015, 142, 214102. [CrossRef]

111. Viñes, F.; Sousa, C.; Illas, F. On the prediction of core level binding energies in molecules, surfaces and solids. Phys. Chem. Chem. Phys. 2018, 20, 8403-8410. [CrossRef]

112. Taucher, T.C.; Hofmann, O.T.; Zojer, E. Final-State Simulations of Core-Level Binding Energies at Metal-Organic Hybrid Interfaces: Artifacts Caused by Spurious Collective Electrostatic Effects. 2020, Submitted.

113. Jackson, J.D. Classical Electrodynamics, 3rd ed.; Wiley: New York, NY, USA, 1999; ISBN 978-0-471-30932-1.

114. Neaton, J.B.; Hybertsen, M.S.; Louie, S.G. Renormalization of Molecular Electronic Levels at Metal-Molecule Interfaces. Phys. Rev. Lett. 2006, 97, 216405. [CrossRef] [PubMed]

115. Lamont, C.L.; Wilkes, J. Attenuation length of electrons in self-assembled monolayers of n-alkanethiols on gold. Langmuir 1999, 15, 2037-2042. [CrossRef]

116. Van der Walt, S.; Colbert, S.C.; Varoquaux, G. The NumPy Array: A Structure for Efficient Numerical Computation. Comput. Sci. Eng. 2011, 13, 22-30. [CrossRef]

117. Hunter, J.D. Matplotlib: A 2D Graphics Environment. Comput. Sci. Eng. 2007, 9, 90-95. [CrossRef]

118. Stukowski, A. Visualization and analysis of atomistic simulation data with OVITO-the Open Visualization Tool. Model. Simul. Mater. Sci. Eng. 2010, 18, 015012. [CrossRef]

119. Momma, K.; Izumi, F. VESTA 3 for three-dimensional visualization of crystal, volumetric and morphology data. J. Appl. Cryst. 2011, 44, 1272-1276. [CrossRef]

120. The GIMP Development Team GIMP 2019. Available online: https://www.gimp.org (accessed on 30 March 2020).

121. Sze, S.M.; Ng, K.K. Physics of Semiconductor Devices, 3rd ed.; Wiley-Interscience: Hoboken, NJ, USA, 2007; ISBN 978-0-471-14323-9.

122. Stähler, J.; Rinke, P. Global and local aspects of the surface potential landscape for energy level alignment at organic-ZnO interfaces. Chem. Phys. 2017, 485-486, 149-165. [CrossRef]

123. Heimel, G.; Rissner, F.; Zojer, E. Modeling the Electronic Properties of $\pi$-Conjugated Self-Assembled Monolayers. Adv. Mater. 2010, 22, 2494-2513. [CrossRef]

124. Natan, A.; Zidon, Y.; Shapira, Y.; Kronik, L. Cooperative effects and dipole formation at semiconductor and self-assembled-monolayer interfaces. Phys. Rev. B 2006, 73. [CrossRef]

125. Egelhoff, W.F. Core-level binding-energy shifts at surfaces and in solids. Surf. Sci. Rep. 1987, 6, $253-415$. [CrossRef]

126. Bagus, P.S.; Nelin, C.J.; Zhao, X.; Levchenko, S.V.; Davis, E.; Weng, X.; Späth, F.; Papp, C.; Kuhlenbeck, H.; Freund, H.J. Revisiting surface core-level shifts for ionic compounds. Phys. Rev. B 2019, 100, 115419. [CrossRef]

127. Vericat, C.; Vela, M.E.; Corthey, G.; Pensa, E.; Cortés, E.; Fonticelli, M.H.; Ibañez, F.; Benitez, G.E.; Carro, P.; Salvarezza, R.C. Self-assembled monolayers of thiolates on metals: A review article on sulfur-metal chemistry and surface structures. RSC Adv. 2014, 4, 27730-27754. [CrossRef]

128. Ma, Z.; Rissner, F.; Wang, L.; Heimel, G.; Li, Q.; Shuai, Z.; Zojer, E. Electronic structure of pyridine-based SAMs on flat $\mathrm{Au}(111)$ surfaces: Extended charge rearrangements and Fermi level pinning. Phys. Chem. Chem. Phys. 2011, 13, 9747. [CrossRef] [PubMed] 
129. Hofmann, O.T.; Deinert, J.-C.; Xu, Y.; Rinke, P.; Stähler, J.; Wolf, M.; Scheffler, M. Large work function reduction by adsorption of a molecule with a negative electron affinity: Pyridine on $\mathrm{ZnO}\left(101^{-} 0\right)$. J. Chem. Phys. 2013, 139, 174701. [CrossRef]

130. Hébert, P.; Le Rille, A.; Zheng, W.Q.; Tadjeddine, A. Vibrational spectroscopic study of the adsorption of pyridine at the $\mathrm{Au}(111)$-electrolyte interface by in situ difference frequency generation. J. Electroanal. Chem. 1998, 447, 5-9. [CrossRef]

131. Stadler, R.; Thygesen, K.S.; Jacobsen, K.W. Forces and conductances in a single-molecule bipyridine junction. Phys. Rev. B 2005, 72, 241401. [CrossRef]

132. Kamenetska, M.; Quek, S.Y.; Whalley, A.C.; Steigerwald, M.L.; Choi, H.J.; Louie, S.G.; Nuckolls, C.; Hybertsen, M.S.; Neaton, J.B.; Venkataraman, L. Conductance and Geometry of Pyridine-Linked Single-Molecule Junctions. J. Am. Chem. Soc. 2010, 132, 6817-6821. [CrossRef]

133. Obersteiner, V.; Egger, D.A.; Zojer, E. Impact of Anchoring Groups on Ballistic Transport: Single Molecule vs Monolayer Junctions. J. Phys. Chem. C 2015, 119, 21198-21208. [CrossRef]

134. Smith, C.E.; Xie, Z.; Bâldea, I.; Frisbie, C.D. Work function and temperature dependence of electron tunneling through an N-type perylene diimide molecular junction with isocyanide surface linkers. Nanoscale 2018, 10, 964-975. [CrossRef]

135. Tsunoi, A.; Lkhamsuren, G.; Mondarte, E.A.Q.; Asatyas, S.; Oguchi, M.; Noh, J.; Hayashi, T. Improvement of the Thermal Stability of Self-Assembled Monolayers of Isocyanide Derivatives on Gold. J. Phys. Chem. C 2019, 123, 13681-13686. [CrossRef]

136. Bagus, P.S.; Staemmler, V.; Wöll, C. Exchangelike Effects for Closed-Shell Adsorbates: Interface Dipole and Work Function. Phys. Rev. Lett. 2002, 89. [CrossRef] [PubMed]

137. Mizushima, H.; Koike, H.; Kuroda, K.; Ishida, Y.; Nakayama, M.; Mase, K.; Kondo, T.; Shin, S.; Kanai, K. Effect of physisorption of inert organic molecules on $\mathrm{Au}(111)$ surface electronic states. Phys. Chem. Chem. Phys. 2017, 19, 18646-18651. [CrossRef] [PubMed]

138. Zangmeister, C.D.; Robey, S.W.; van Zee, R.D.; Kushmerick, J.G.; Naciri, J.; Yao, Y.; Tour, J.M.; Varughese, B.; Xu, B.; Reutt-Robey, J.E. Fermi Level Alignment in Self-Assembled Molecular Layers: The Effect of Coupling Chemistry. J. Phys. Chem. B 2006, 110, 17138-17144. [CrossRef] [PubMed]

139. Kim, B.; Beebe, J.M.; Jun, Y.; Zhu, X.Y.; Frisbie, C.D. Correlation between HOMO Alignment and Contact Resistance in Molecular Junctions: Aromatic Thiols versus Aromatic Isocyanides. J. Am. Chem. Soc. 2006, 128, 4970-4971. [CrossRef] [PubMed]

140. Macdonald, J.R.; Barlow, C.A. Work Function Change on Monolayer Adsorption. J. Chem. Phys. 1963, 39, 412-422. [CrossRef]

141. Maschhoff, B.L.; Cowin, J.P. Corrected electrostatic model for dipoles adsorbed on a metal surface. J. Chem. Phys. 1994, 101, 8138-8151. [CrossRef]

142. Gershevitz, O.; Sukenik, C.N.; Ghabboun, J.; Cahen, D. Molecular Monolayer-Mediated Control over Semiconductor Surfaces: Evidence for Molecular Depolarization of Silane Monolayers on Si/SiOx. J. Am. Chem. Soc. 2003, 125, 4730-4731. [CrossRef]

143. De Renzi, V.; Rousseau, R.; Marchetto, D.; Biagi, R.; Scandolo, S.; del Pennino, U. Metal Work-Function Changes Induced by Organic Adsorbates: A Combined Experimental and Theoretical Study. Phys. Rev. Lett. 2005, 95, 046804. [CrossRef]

144. Fukagawa, H.; Yamane, H.; Kera, S.; Okudaira, K.K.; Ueno, N. Experimental estimation of the electric dipole moment and polarizability of titanyl phthalocyanine using ultraviolet photoelectron spectroscopy. Phys. Rev. B 2006, 73, 041302. [CrossRef]

145. Cornil, D.; Olivier, Y.; Geskin, V.; Cornil, J. Depolarization Effects in Self-Assembled Monolayers: A Quantum-Chemical Insight. Adv. Funct. Mater. 2007, 17, 1143-1148. [CrossRef]

146. Sushko, M.L.; Shluger, A.L. Intramolecular Dipole Coupling and Depolarization in Self-Assembled Monolayers. Adv. Funct. Mater. 2008, 18, 2228-2236. [CrossRef]

147. Piacenza, M.; D’Agostino, S.; Fabiano, E.; Della Sala, F. Ab initio depolarization in self-assembled molecular monolayers: Beyond conventional density-functional theory. Phys. Rev. B 2009, 80, 153101. [CrossRef]

148. Blumenfeld, M.L.; Steele, M.P.; Monti, O.L.A. Near- and Far-Field Effects on Molecular Energy Level Alignment at an Organic/Electrode Interface. J. Phys. Chem. Lett. 2010, 1, 145-148. [CrossRef] 
149. Wang, L.; Rangger, G.M.; Romaner, L.; Heimel, G.; Bučko, T.; Ma, Z.; Li, Q.; Shuai, Z.; Zojer, E. Electronic Structure of Self-Assembled Monolayers on Au(111) Surfaces: The Impact of Backbone Polarizability. Adv. Funct. Mater. 2009, 19, 3766-3775. [CrossRef]

150. Koller, G.; Winter, B.; Oehzelt, M.; Ivanco, J.; Netzer, F.P.; Ramsey, M.G. The electronic band alignment on nanoscopically patterned substrates. Org. Electron. 2007, 8, 63-68. [CrossRef] 